\title{
The Impact of Age, Gender, and Marital Status on Age-Associated Cognitive Decline
}

\author{
Katerine-Ann MacKinnon-Lee, Mark Bahr \\ Bond University, Queensland, Australia \\ Email: katerine-ann.mackinnon-lee@student.bond.edu.au
}

How to cite this paper: MacKinnon-Lee, K.-A., \& Bahr, M. (2020). The Impact of Age, Gender, and Marital Status on Age-Associated Cognitive Decline. Psychology, 11, 1236-1283. https://doi.org/10.4236/psych.2020.118082

Received: July 3, 2020

Accepted: August 28, 2020

Published: August 31, 2020

Copyright $\odot 2020$ by author(s) and Scientific Research Publishing Inc. This work is licensed under the Creative Commons Attribution International License (CC BY 4.0).

http://creativecommons.org/licenses/by/4.0/

\begin{abstract}
Age-associated cognitive decline is a normal, non-pathological and inevitable human occurrence. Therefore, it remains a research priority to assess the role of certain protective factors, such as age, gender, and marital status, that influence age-associated cognitive decline to intervene in the stemming of its progress and guide theory, policy, and practice. The study used a dissociative paradigm, using two measures to assess both short-term and visuo-spatial memory, to clarify the unestablished results of whether cognitive ageing occurs in one subsystem (i.e., modular) or across the whole brain (i.e., generalised). Participants $(N=126 ; 79$ females and 46 males) from Sydney, New South Wales were recruited and divided into three age groups: $18-27,27-62$, and 62+. Participants completed an online questionnaire, with computer administered tasks, assessing visuo-spatial and short-term memory. A Multivariate Analysis of Covariance (MANCOVA) revealed no significant covariate effects; covariates entered included participants' total scores from psychometrically established measures addressing engagement with social networks, depressive symptomology, personal wellbeing, and resilience. Consistent with previous findings, results from a $\mathrm{Mul}$ tivariate Analysis of Variance (MANOVA) supported the notion that being married is a protective factor in slowing down the progression of age-associated cognitive decline (i.e., visuo-spatial memory), in comparison to being single or in a de facto relationship. Older adults who were married performed lower on visuo-spatial memory tasks than younger adults. Support for the generalised model of ageing was revealed. Future directions and implications of the study's findings indicate the need to maximise protective interventions for those who are single or in a de facto relationship, and the brain as a whole system, to prevent unwarranted cognitive decline.
\end{abstract}

\section{Keywords}

Cognitive Decline, Ageing, Marital Status, Gender, Cognitive Reserve, Generalised Decline 


\section{Introduction}

Age-associated cognitive decline is considered a hallmark of ageing, hence a normal, non-pathological human occurrence (Deary et al., 2009). As a result of advancing age, cognitive decline is associated with a deterioration in certain cognitive abilities, such as processing speed, language, memory, and executive functioning abilities (Crook et al., 1992; Harada, Natelson-Love, \& Triebel, 2013). Cognitive ageing is detectable in early adulthood, including healthy educated adults (Salthouse, 2009; Salthouse, 2011) and a common precursor of dementia, illness, and death (Deary et al., 2009). However, the progress and severity of age-associated cognitive decline are variable (Stern, 2009). Certain individual differences may contribute to higher levels of cognitive reserve, aiding in the mitigation of cognitive ageing and protection of brain health (Cornwell \& Waite, 2009; Deary et al., 2009). It is predicted that between 2015 and 2050, 22\% of the world's population will be over the age of 60 , with the number of people aged 65 or older, outnumbering children under the age of five (World Health Organisation [WHO], 2018). As such, the projected increase in the ageing population will place significant added pressure on the individual, family, societal, and economical resources (Centres for Disease Control and Prevention and the Alzheimer's Association, n.d.; Deary et al., 2009; Kremen, Lachman, Pruessner, Sliwinski, \& Wilson, 2012). This indicates that a research priority and public health goal remains to better understand the role of protective factors with a view of impeding unwarranted cognitive ageing.

Literature has claimed that, as a function of age, there is decreased flexibility in cognitive function, especifically areas of "fluid" cognitive ability involving memory, executive functioning, and processing speed and reasoning, which are all requirements for everyday independence (Deary et al., 2007). Spatial memory involves the retention of the location or position of objects or places and has been found to be particularly sensitive to age-associated cognitive decline, more so than verbal cognition (Cornoldi \& Vecchi, 2003; Iachini et al., 2009). This difference in the spatial domain compared to that of the verbal domain may be due to cognitive reserve, arising from verbal encoding of explicit knowledge. The existence of multiple redundant verbal associations provides alternate retrieval mechanisms for verbally encoded material. This may buffer damage to verbally encoded associations, hence an explanation to the robust age-related differences in spatial and verbal memory (Jenkins, Myerson, Joerding, \& Hale, 2000).

Consequently, findings from previous studies suggest decline in visuo-spatial memory to be predictive of age-associated cognitive decline (Caroll, 2015; Holden \& Gilbert, 2012; Hort et al., 2007). Further, a limited number of studies have used visuo-spatial memory as a measurement of cognitive ageing. The MMSE has been widely used in the ageing literature to screen dementia; however, its ability to be able to detect more subtle age-associated cognitive changes is questionable (Berteau-Pavy, Park, \& Raber, 2007). The Novel Image-Novel Location (NINL; Rizk-Jackson et al., 2006) is a sensitive measure to assess visuo-spatial 
memory in neurotypical elderly. Further, the use of visuo-spatial memory over verbal memory allows for test fairness across all educational levels and age groups (Raber, 2015). Rodent models have been used to study cognitive ageing using location and object novelty recognition tasks, finding sex and age differences (Benice \& Raber, 2009; Bernice, Rizk, Kohama, Pfankuch, \& Raber, 2006). Performance on the NINL is sensitive to the effects of a gene allele (i.e., apolipoprotein E4), which is a known risk factor for developing late onset Alzheimer's disease (Berteau-Pavy et al., 2007; Haley, Berteau-Pavy, Park, \& Raber, 2010; Raber, 2015). For this reason, the current study aimed to contribute to the research by the use of an extension of the NINL, namely, The Bond Novel Image Novel Location-Revised (NINL_BR; Carroll \& Bahr, 2015) to assess visuo-spatial memory in an Australian community sample, ensuring age-related changes were conservatively detected.

The cognitive reserve hypothesis posits that cognitive stimulation can act as a protective factor against cognitive decline (Stern, 2009). Individuals who have higher levels of cognitive reserve, which refers to the brain's ability to actively cope and function after cognitive deterioration, are more likely to maintain higher levels of cognitive performance (Satz, 1993; Stern, 2009). Research has suggested that higher socio-economic status, bi- or multilingualism, level of education, IQ, occupational complexity, proposition of relationships (e.g., marriage) in comparison to living alone, and social networks can buffer and delay cognitive ageing processes, hence contribute to higher cognitive reserve (Baltes \& Baltes, 1990; Coyle, 2003; Craik, Bialystok, \& Freedman, 2010; Crooks et al., 2008; Elovainio et al., 2018; Fratiglioni \& Wang, 2007; Håkansson et al., 2009; Mazzuco, Meggiolaro, Ongaro, \& Toffolutti, 2017; Mousavi-Nasab et al., 2012; Stern, 2009; Perquin et al., 2013; Van Gelder et al., 2006; Yates, Clare, \& Woods, 2017). It has also been suggested that women have more positive exchanges with children, other family, and friends compared to men and these positive exchanges may be indicative of greater cognitive stimulation for women than men (Stafford et al., 2011). In addition to age-associated cognitive decline, an individual's social and emotional life does change as a function of increasing age (Charles \& Carstensen, 2010). Widowhood is a more common marital state for the elderly (Lee, DeMaris, Bavin, \& Sullivan, 2001; Lubben, 1988), increasing loneliness, stress, and depression. This can cause intellectual and cognitive stimulation gained from relationships to be reduced (Paul \& Ribeiro, 2009), accelerating cognitive decline (Lucanin, Lucanin, \& Mladen, 2011; Meng, Liu, Liu, Fang, \& Zhai, 2018; Ownby, Crocco, Acevedo, John, \& Loewenstein, 2006; Turner, Capuano, Wilson, \& Barnes, 2015; Wilson, Mendes de Leon, Bennett, Bienias, \& Evans, 2004). Research has shown that personal wellbeing, or lack thereof, may be associated with cognitive changes, for example, individuals who view their ageing positively, will be more likely to actively exploit their cognitive resources (Levy, 2003; West, Thorn, \& Bagwell, 2003). Further, studies have found that resilience and social integration promote wellbeing and reduce the rate of cognitive decline (Ertel, Glymour, \& Berkman, 2008; Tschanz et al., 2013). The need 
to control for each participant's expected cognitive reserve factors can be justified to ensure that age-related cognitive changes are not confounded. As a consequence, the current study examined the impact of age, gender, and marital status on non-pathological cognitive ageing, after controlling for the effects of expected cognitive reserve factors (i.e., depressive symptomology, resilience, personal wellbeing, and engagement with social networks), due to their suggested salience.

The current study aimed to extend upon the findings from Caroll's (2015) study, which examined the impact of conjugal loss on age-associated cognitive decline. Carroll's (2015) findings revealed that those who had lost a partner (i.e., widowed) performed lower on cognitive performance (i.e., visuo-spatial memory tasks) as well as having slower reaction times, compared to non-widowed participants. Caroll's (2015) study implemented the use of a sensitive construct (i.e., visuo-spatial memory; Iachini et al., 2009) to measure cognitive ageing; however, the study did possess a number of limitations. For example, while there was no significant covariate effect for social support, the utilisation of a well-established psychometrically sound measure was absent. Instead, simple demographics for the assessment of social support were collected that lacked uniformity, and whether the effects of marital status on cognitive functioning are still evident after controlling for participant's engagement with social networks remains largely unknown. Further, the small Queensland sample size used in Caroll's (2015) study $(N=59)$ may have restricted its ability to distinguish gender effects. Consequently, the current study aimed to address these limitations and extend the generalisability and interpretation of Caroll's (2015) findings in the examination of age, gender, and marital status on age-associated cognitive decline. To increase power, the current study aimed to use a larger sample compared to Caroll's (2015) study (Shadish, Cook, \& Campbell, 2002). State-specific Queensland factors were excluded by sampling from different areas of Sydney, New South Wales, to increase generality. By addressing these limitations in the cognitive ageing literature, the current study may guide future research efforts and psychological and social intervention strategies tailored to individuals who have deficits in cognitive protective factors, hence, improve the wellbeing of older adults.

Further empirical studies, in alignment with the cognitive reserve hypothesis have supported the proposition of relationships (e.g., marriage) acting as protective factors against age-associated cognitive decline, in comparison to living alone (Håkansson et al., 2009; Mousavi-Nasab et al., 2012). In accordance with these findings are the results from a longitudinal study by Mazzuco et al. (2017), whose sample comprised of Northern Europeans $(N=1276)$. The researchers showed that co-residence with a partner or with adult children reduced cognitive decline in older adults in comparison to those living alone, even if their cognitive status was already being compromised. The findings relating to cognitive decline were measured by differences in scores from 2004 to 2006-07 via five different measures of cognitive function. These included, orientation, immediate recall, 
delayed recall, verbal fluency, and numeracy tests. However, in their Southern European (i.e., Italy and Spain) sample $(N=1142)$, co-residence with others, was negatively associated with the cognitive health of older adults (Mazzuco et al., 2017). Further, the study did not show whether gender had an effect on cognitive ageing. Studying both men and women allows both biological mechanisms to be considered and their association with cognitive decline. Notably, the researchers' contradictory findings could have been because selection bias was not controlled. There was also no provision made for the differences in the level of co-residence of older people with adult children as well as institution variability across Northern and Southern Europe (Gaymu et al., 2006). Therefore, the current study aimed to overcome this methodological problem by purposively sampling men and women of differing marital statuses residing from one country (i.e., Australia) to add to the external validity of findings.

Further review of the cognitive ageing literature has found shortfalls in the examination of age, gender, and marital status on age-related cognitive decline. A longitudinal study $(N=1416)$ by Van Gelder et al. (2006) revealed that European men aged between 70 - 89 years old, who were unmarried or lived alone during a five-year period showed greater cognitive decline compared to those men who were married or who lived with someone during this five-year period. As there was no provision or control regarding participant's engagement with social networks in either marital status or living arrangement in the aforementioned study, the researchers' finding was not decisive, compromising the external validity of their findings. Hence, the present study controlled for the expected confounding effects of each participant's engagement with social networks on cognitive ageing and marital status by using an established measure with sound psychometric properties, such as the Lubben Social Network Scale (LSNS; Lubben \& Gironda, 2003). Moreover, Van Gelder et al.'s (2006) study measured cognitive decline by the Mini-Mental State Examination (MMSE; Folstein, Folstein, \& McHugh, 1975), which is a measure of global cognitive functioning. Thus, the detailed assessment of different cognitive domains remained absent. As a result, the current study addressed this limitation by measuring the cognitive domain of visuo-spatial memory, due to its sensitivity to age-associated cognitive changes (Holden \& Gilbert, 2012; Hort et al., 2007; Iachini et al., 2009).

In contrast to visuo-spatial memory, evidence suggests that short-term memory (STM) may remain unaffected as a function of age. STM has been differentiated into two processes, which include, primary memory and true working memory (Luo \& Craik, 2008). Both primary and true working memory involves the simple storage of information, however, true working memory manipulates information. Previous studies assessing STM using forward digit span tasks have found that span remains unaffected by age (Harrison, Rosenblum, \& Currie, 2010). This indicates that STM shows little decline in those with mild cognitive impairment and Alzheimer's disease compared to healthy individuals (Gronholm-Nyman, Rinne, \& Laine, 2009; Traykov et al., 2007). Two disease process 
models have been identified to explain cognitive ageing processes: generalised and modular decline. Under the generalised model, the brain as a whole is subject to decline; the accumulation of amyloid plaque, attacking neurological structures unsystematically, has been suggested to primarily influence widespread cognitive decline (Hardy, 2002; Salthouse, 1996). The modular decline model presents an alternative view, which posits that cognitive decline is ordered and predictable with specific sub-systems declining separately, implying that cognitive preservation is differential (Delaloye et al., 2009). While the cognitive reserve hypothesis does not favour either model of cognitive ageing, the idea of differential preservation in cognition is proposed (Stern, 2009). Therefore, the current study implemented a dissociative paradigm, using two measures to assess both STM and visuo-spatial memory. A forward digit span task (DST) to assess STM was used as a comparison to the measure of interest (i.e., NINL_BR), which assessed visuo-spatial memory.

\section{The Current Study}

Based on the empirical literature reviewed, the following was hypothesised.

$\mathrm{H}_{1}$ : After controlling for expected cognitive reserve factors, participants who were in married or de facto relationships would have significantly higher visuo-spatial memory scores than those participants who were single or widowed.

$\mathrm{H}_{2}$ : After controlling for expected cognitive reserve factors, older-aged males would have significantly lower visuo-spatial memory scores compared to older-aged females.

$\mathrm{H}_{3}$ : In support of the modular decline of ageing, there would be a significant dissociation of performance with age, with DST performance (i.e., STM) remaining unaffected by age, however, performance on the NINL_BR (i.e., visuo-spatial memory) would show decline as a function of age. Conversely, in support of the generalised model of ageing, there would be no significant difference in DST and NINL_BR performance as age increases.

\section{Method}

\subsection{Participants}

Participants were recruited via a purposive sampling approach from either social networking sites (e.g., Facebook) or an email, which included the friends, family, and acquaintances of the student researcher that resided in Sydney, New South Wales. Inclusion criteria required respondents to provide informed consent, be aged over 18, and have access to an internet connected electronic device. One hundred and forty questionnaire responses were completed and this exceeded the minimum sample size $(N=135)$ required to obtain a medium effect size ( $f=$ 0.15 ), power of 0.80 , and a critical alpha of 0.05 , using $G^{*}$ Power as a validation tool a priori (Faul, Erdfelder, Lang, \& Buchner, 2007).

Originally, marital status was categorised into six categories: married, de facto, single, widowed, divorced, new relationship, and divorced, single. For the pur- 
poses of the study and to ensure sufficient cell sizes, the divorced, new relationship $(n=1)$ was collapsed into the married category and the divorced, single ( $n$ $=2$ ) was collapsed into the single category. Insufficient cell sizes were observed for the widowed category $(n=14)$ and collapsing of cells was not an option for this particular category. Therefore, a decision was made to remove the widowed category, leaving marital status comprising married, de facto, and single. Consequently, the total analytical sample consisted of 126 participants, ranging between 18 and 92 years old ( $M=45.79$ years, $S D=22.23$ years). Age was categorised into three groups (18 - 27, $27-62$, and 62+). This was done to achieve an age-balanced design and to broadly correspond to other ageing research in the categorisation of young, middle-aged, and old people (Byers, Yaffe, Covinsky, Friedman, \& Bruce, 2010).

The sample comprised 79 females (63.2\%) and 46 males (36.8\%). Forty-eight participants (38.4\%) were between 18 and 27, 43 participants (34.4\%) were between 27 - 62, and 34 (27.2\%) participants were above 62 years old. Of the total sample, 18 participants (14.3\%) were in a de facto relationship, 65 participants (51.6\%) were married, and 38 participants (30.2\%) were single. See Table 1 for distribution of independent variables (i.e., marital status, age, and gender). A chi-square test revealed that the gender distribution in the current sample was not representative of the Australian population based on gender norms from the Australian Bureau of Statistics (ABS, 2017), $p=0.003$ (see Appendix A).

\subsection{Materials}

Socio-demographic questionnaire. The 3-item socio-demographic questionnaire obtained information, including each participant's current age in years, gender, and marital status.

The Lubben Social Network Scale - 6 (LSNS-6; Lubben \& Gironda, 2003) is a six-item scale which is further divided into two subscales evaluating family and friendship ties. Total LSNS-6 scores are an equally weighted sum of these six items, with scores ranging from zero to 30 . Higher scores are reflective of larger social networks. The LSNS-6 has demonstrated sound psychometric properties, supporting its use in research and clinical contexts (Gray, Kim, Ciesla, \& Yao, 2016).

The Novel Item Novel Location-Bond Revised (NINL_BR; Carroll \& Bahr, 2015) objectively examines visuo-spatial memory in adults. The NINL_BR

Table 1. Distribution of marital status by age and gender.

\begin{tabular}{ccccccc}
\hline \multirow{2}{*}{ Marital Status } & \multicolumn{2}{c}{$18-27$} & \multicolumn{2}{c}{$27-62$} & \multicolumn{2}{c}{$62+$} \\
\cline { 2 - 6 } & Male & Female & Male & Female & Male & Female \\
\hline Married & 2 & 1 & 9 & 26 & 8 & 17 \\
De facto & 4 & 9 & 2 & 2 & 0 & 1 \\
Single & 19 & 13 & 0 & 2 & 1 & 3
\end{tabular}

Note: Valid $\mathrm{N}=119$. Missing $\mathrm{N}=7$. Total $\mathrm{N}=126$. 
was derived from the Novel Image Novel Location (NINL; Rizk-Jackson et al., 2006) and contains similar stimuli. The NINL_BR is administered online and participants are first presented with the Learning Phase, which consists of the presentation of 24 sets of slides containing three images of everyday items, with each slide shown for eight seconds (refer to Figure 1). Each slide is split into four quadrants, with one quadrant always remaining imageless. The instructions in the Learning Phase ask the participant to remember the images and their positioning on the slide.

The Test Phase comprises 24 slides, with the images either remaining the same as in the Learning Phase, labelled, No Change (NC); an unseen image, labelled, New Image (NI); or a change in image position to an empty quadrant, labelled, New Location (NL; refer to Figure 2). For the purposes of this study, three scores were created: Proportion NC, Proportion NI (i.e., content memory), and Proportion NL (i.e., content and spatial memory), and these scores capture the correct recognition and identification of an image from the Learning Phase. A participant's total score ranges from zero to 24 and is reflective of their overall memory performance. Higher scores indicate a more precise recall of the Learning Phase in the Test Phase. The NINL_BR has demonstrated good test-retest reliability, convergent, and divergent validity (Berg, 1988; Caroll, 2015; Hayley et al., 2012; Rizk-Jackson et al., 2006).
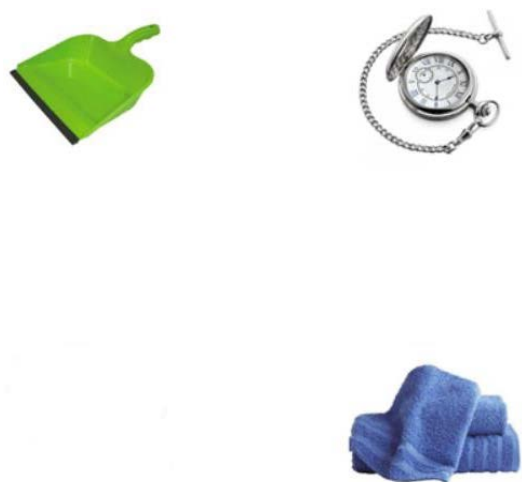

Figure 1. Learning phase example from the NINL_BR.
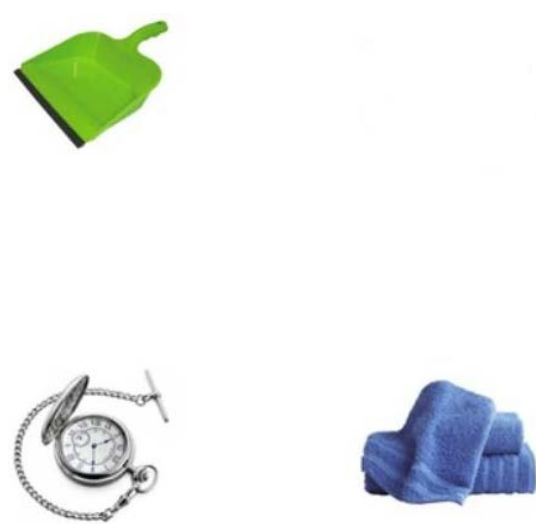

Figure 2. Test phase example from the NINL_BR, revealing a change in location (NL). 
Forward Digit Span Task (DST). DSTs are popularly used in cognitive psychology, neuropsychological testing, and experimental research as a test of short-term verbal memory (Franzen, Robbins, \& Sawicki, 1989; Lezak, 1983; Richardson, 2007). The purpose of employing an online forward DST in the current study was for comparison to the measure of interest (i.e., NINL_BR). Participants were shown a set of slides with sequences of 11 random numbers. Each slide was shown for eight seconds after which it blanked and participants then recalled as many of the numbers they could remember in the correct order presented. Each participant's mean digit span was used for the analysis as an indicator of short-term storage capacity (Myerson, Emery, White, \& Hale, 2003).

The Depression, Anxiety, and Stress Scale (DASS 21; Lovibond \& Lovibond, 1995) is a 21 item scale that measures the severity of three states of self-reported negative affect: depression, anxiety, and stress symptoms experienced over the past week in adults (Lovibond \& Lovibond, 1995). The use of the DASS 21 in the present study allows for comparable scores using local Australian norms across age, sex, and education (Crawford et al., 2011). The DASS 21 has demonstrated sound psychometric properties, with notably good reliability in adult non-clinical samples, supporting its use in the current study (Henry \& Crawford, 2005; Sinclair et al., 2012). The DASS 21 has also revealed good convergent and divergent validity (Brown et al., 1997; Gloster et al., 2008; Crawford \& Henry, 2003; Ng et al., 2007; Norton, 2007; Sinclair et al., 2012; Wood et al., 2010). Consequently, the DASS 21 was used to operationalise depressive symptomology in the current study.

The Personal Wellbeing Index-Adult; Fifth Edition (PWI-A, 5th Edition; International Wellbeing Group (IWG), 2013) is a 7-item self-report measure used to assess subjective satisfaction in adults over the age of 18 . The PWI-A addresses seven different facets of life including standard of living, personal health, achievement, personal relationships, personal safety, community-connectedness, and future security (International Wellbeing Group (IWG), 2013). The total PWI-A score ("Subjective Wellbeing") is obtained by summing the seven domain scores, with higher scores reflective of greater personal wellbeing (International Wellbeing Group (IWG), 2013). Scores range from zero to 100. In the interests of psychometrics, the current study used a standard scoring system for the PWI-A. The PWI-A has demonstrated good psychometrics in cross-cultural samples (Diener, Emmons, Larsen, \& Griffin, 1985; Lau \& Cummins, 2005; Lau, Cummins, \& McPherson, 2005; Misajon et al., 2016; Tomyn, Fuller Tyszkiewicz, \& Cummins, 2013; Yousefi, Alipour, \& Sharif, 2011).

The Resilience in Midlife Scale (RIM Scale; Ryan \& Caltabiano, 2009) measures resilience (self-reported) in adults between the ages of 35 and 60. The RIM Scale contains 25 items that tap five facets of resilience, such as perseverance, internal locus of control, self-efficacy, adaptation and coping, and family or social networks (Ryan \& Caltabiano, 2009). Scores range from zero to 100, with higher scores reflective of greater resilience. The RIM Scale has demonstrated good internal consistency $(\alpha=0.87)$ and split-half reliability $(r=0.88)$ in 
a non-clinical Australian sample of 130 adults (Ryan \& Caltabiano, 2009) and was used to operationalise resilience in this study.

Refer to Appendix B for instrumentation and Appendix C for reliability statistics for scales.

\subsection{Procedure}

Prior to data collection the study was approved by the Bond University Human Research Ethics Committee (BUHREC; BUHREC \#RO15061) and conducted in alignment with the National Statement (2007). Participants were provided with a link, which directed them to the online questionnaire platform, Google Forms, a web-based software offered by Google within its Google Drive service. An explanatory statement was provided (see Appendix B). Participants who voluntarily selected that they understood informed consent were able to proceed, inferring participation. After a three-month data collection period, the data was directly exported to the IBM Statistical Package for the Social Sciences (SPSS) version 25 for statistical screening and analysis. The data was only accessible by the researcher and will be stored with a password protected file for five years at Bond University, in accordance with the guidelines set out by BUHREC.

\subsection{Design}

The current study employed a 3 (Marital Status: de facto; married; single) $\times 3$ (Age Group: 18 - 27; 27 - 62; 62+) × 2 (Gender: male; female) between subjects Multivariate Analysis of Covariance (MANCOVA) to examine the relationship between marital status, age, and gender on age-associated cognitive decline after controlling for each participant's expected cognitive reserve factors. Each participant's total scores from the measures (i.e., LSNS-6, DASS 21, RIM Scale, and PWI-A) were entered as covariates to control for their expected confounding effects on their cognitive reserve. Age, gender, and marital status were entered as independent variables. Visuo-spatial memory, as measured by the NINL_BR subscales (i.e., New Image, New Location, and No Change) and STM, as measured by the DST, were entered as dependent variables. As nocovariates were detected, the initial analysis was followed with a 3 (Marital Status: de facto; married; single) $\times 3$ (Age Group: 18 - 27; 27 - 62; 62+) × 2 (Gender: male; female) between subjects Multivariate Analysis of Variance (MANOVA), with follow up Analyses of Variance (ANOVAs). A mixed ANOVA was also performed to test the third hypothesis. All analyses were conducted with a conventional alpha level set at 0.05 a priori (Tabachnick \& Fidell, 2014).

\section{Results}

\subsection{Data Diagnostics}

Data was screened to ensure assumptions were met for the MANCOVA, MANOVA, and ANOVAs. The assumption of homogeneity of variance for the New Location subdomain of the NINL_BR was violated. Univariate and multi- 
variate outliers were present, however, all outliers were accepted as genuine extreme cases and preserved in the analysis. All other assumptions were met. MANCOVA and MANOVA are robust to allow for the above assumption violations. A conservative approach was taken for the analysis by using the Pillai's Trace approximation of $F$ (Tabachnick \& Fidell, 2014).

\section{MANCOVA Analysis: Marital Status $\times$ Age $\times$ Gender}

A $3 \times 3 \times 2$ MANCOVA analysis was conducted. No statistically significant covariate effects on the combined dependent variables (i.e., NINL_BR and DST) for the DASS 21, $F(4,91)=1.20, p=0.317$; RIM Scale, $F(4,91)=2.13, p=0.084$; PWI-A, $F(4,91)=0.21, p=0.934$, and LSNS-6, $F(4,91)=0.54, p=0.708$, were revealed. As such, all covariates for the remaining analyses were removed, despite their theoretical importance, as they demonstrated no significant effect on cognition.

\section{MANOVA Analysis: Marital Status $\times$ Age $\times$ Gender}

A $3 \times 3 \times 2$ between subjects MANOVA was conducted. No significant multivariate interaction effect amongst gender, marital status, and age on the combined dependent variables was observed, $F(8,202)=1.13, p=0.342$. Similarly, no significant multivariate interaction effect was found between gender and marital status, and gender and age, on the combined dependent variables, $F(8,202)$ $=0.45, p=0.889$ and $F(8,202)$. A significant multivariate interaction effect was found between marital status and age on the combined dependent variables, indicating that the effect of cognitive decline is not the same for those who are of differing marital statuses and ages, $F(16,412)=1.88, p=0.020$, Pillai's trace $=$ $0.27, \eta^{2}=0.07$, power $=0.96$. There was no significant multivariate effect of gender on the combined dependent variables, $F(4,100)=0.64, p=0.638$. Conversely, a significant multivariate effect of marital status on the combined dependent variables was obtained, indicating that marital status had a direct effect on cognitive performance, $F(8,202)=2.36, p=0.019$, Pillai's trace $=0.17, \eta^{2}=$ 0.09 , power $=0.88$. There was also a significant multivariate effect of age on the combined dependent variables, indicating that age had a direct impact on cognitive performance, $F(8,202)=3.17, p=0.002$, Pillai's trace $=0.22, \eta^{2}=0.11$, power $=0.96$.

Inspection of between-subjects effects demonstrated a significant interaction effect between marital status and age on the New Location and New Image subdomain of the NINL_BR, $F(4,103)=3.78, p=0.007, \eta^{2}=0.13$, power $=0.88$ and $F(4,103)=2.89, p=0.026, \eta^{2}=0.10$, power $=0.76$, respectively. Further, a significant effect for marital status on New Location and New Image were found, $F(2,103)=4.56, p=0.013, \eta^{2}=0.08$, power $=0.76$ and $F(2,103)=3.19, p=$ $0.045, \eta^{2}=0.06$, power $=0.60$, respectively. These findings indicate that scores on the New Location and New Image subdomain of the NINL_BR are different for those of differing marital statuses. A significant between-subjects effect for age and New Location was found, indicating that age had a direct impact on New Location scores, $F(2,103)=8.59, p<0.001, \eta^{2}=0.14$, power $=0.96$. 
One-way ANOVAs. Two ANOVAs were conducted on a series of variables to examine more specifically the impact of marital status and age on the New Location and New Image subdomains of the NINL_BR. Using SPSS, the marital status file was split. No significant difference was found between those who were in a de facto relationship or single on New Location scores, $F(2,15)=0.08, p=$ 0.924 and $F(2,35)=0.29, p=0.753$, respectively, and New Image scores, $F(2,15)$ $=1.98, p=0.173$ and $F(2,35)=1.26, p=0.296$, respectively. However, for those participants who identified as being married there was a statistically significant difference on New Location scores, $F(2,61)=28.52, p<0.001, \eta^{2}=0.47$, power approaching one, and New Image scores, $F(2,61)=4.28, p=0.018, \eta^{2}=0.12$, power $=0.73$. These results indicate that those who were married performed better on the New Location and New Image subdomain of the NINL_BR than those who were single or in a de facto relationship.

Post-hoc comparisons between groups for New Location, using the Tukey HSD test $(\alpha=0.05)$ indicated a floor effect. Inspection of means between groups using the Tukey HSD test $(\alpha=0.05)$ suggested that New Image scores for those who were married and aged between 27 and 62 were significantly higher compared to those who were married and aged over 62. New Image scores of the NINL_BR were significantly lower for those who were married and aged between 18 and 27 compared to the two other age groups. Further, for those who were single and in a de facto relationship no significant difference in New Image scores across age were found. A problem of interpretation remains as some cell sizes are small, revealing zero variation $(M=0.0, S D=0.0)$, therefore the obtained result should be treated with caution (Tabachnick \& Fidell, 2014). See Table 2 for means and standard deviations.

\subsection{Generalised Versus Modular Decline}

Mixed ANOVA. The standardised ( $Z$ ) scores of the total NINL_BR and DST were obtained for a directly comparable effect to test the third hypothesis. This was done as the NINL_BR utilised proportional scales, while the DST utilised a scaling system out of seven. Age was entered as the independent variable. The assumption of sphericity was met, Greenhouse-Geisser epsilon $=1.00$. No significant multivariate interaction effect was shown for type of measure on age, $F(2,122)=0.13, p=0.878$, indicating no significant effect of age on NINL_BR and DST performance. Further, no significant multivariate effect was found for

Table 2. Means and standard deviations of new image scores by marital status and age.

\begin{tabular}{cccc}
\hline \multirow{2}{*}{ Marital Status } & $18-27$ & $27-62$ & $62+$ \\
\cline { 2 - 4 } & $\mathrm{M}(\mathrm{SD})$ & $\mathrm{M}(\mathrm{SD})$ & $\mathrm{M}(\mathrm{SD})$ \\
\hline Married & $0.29(0.14)$ & $0.67(0.24)$ & $0.66(0.20)$ \\
De facto & $0.70(0.10)$ & $0.59(0.21)$ & $0.0(0.0)$ \\
Single & $0.67(0.16)$ & $0.81(0.09)$ & $0.59(0.12)$ \\
\hline
\end{tabular}

Note. $\mathrm{N}=126 . \mathrm{M}=$ Mean. $\mathrm{SD}=$ Standard Deviation. 
type of measure (i.e., NINL_BR and DST), $F(1,122)=0.0, p=0.952$, supporting the model of generalised ageing. A declining trend in NINL_BR and span performance for participants aged between 27 and 62 was observed (see Figure 3). However, these visual observations are made with caution due to no statistical difference of age detected.

\section{Discussion}

MANCOVA results suggested that expected cognitive reserve factors had no effect on age-associated cognitive decline and if kept the study would have decreased power (Tabachnick \& Fidell, 2014). Differences in the current study's sample in comparison to previous studies may explain differences in efficacy of covariates. Results from the $3 \times 3 \times 2$ MANOVA indicated a significant interaction between marital status and age on the New Location and New Image subdomains of the NINL_BR. Follow-up ANOVAs revealed that those who were married obtained significantly higher scores on the subdomains of New Location (i.e., content and spatial memory) and New Image (i.e., content memory) of the NINL_BR than those who were single or in a de facto relationship. Thus, the first hypothesis was partially supported.

Previous studies have found that those who are married or living with someone (e.g., adult children, partner) show significantly lower cognitive decline compared to those who are single or living alone (Aartsen et al., 2005; Caroll, 2015; Elovainio et al., 2018; Håkansson et al., 2009; Mousavi-Nasab et al., 2012; Van Gelder et al., 2006). The findings in the current study were partially consistent with previous studies, revealing married participants demonstrating significantly less cognitive decline (indicated by significantly higher visuo-spatial memory scores) than participants who were single. However, inconsistent with previous studies, the current study found that those in a de facto relationship did

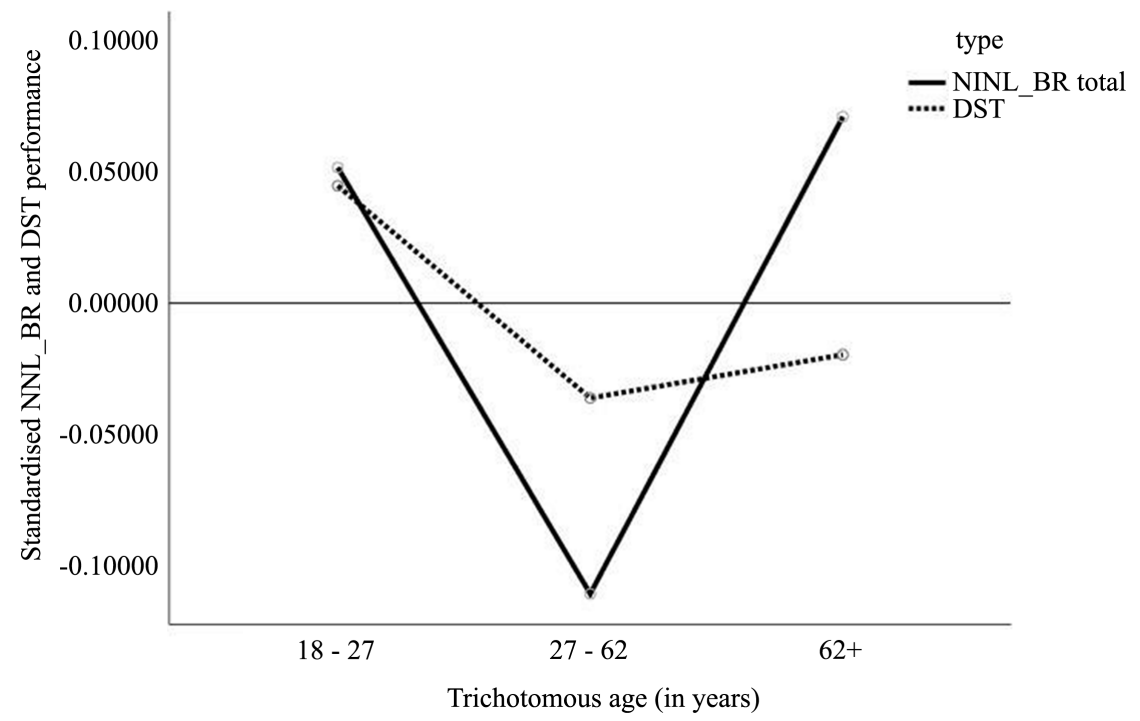

Figure 3. Standardised total NINL_BR and DST scores across age. Reference line indicates sample mean level of performance. 
not demonstrate to have significantly higher visuo-spatial memory scores compared to those who identified as being single. While it was expected that those participants who were single to perform significantly lower on visuo-spatial memory scores than those who were married, it was unexpected to find that those in a de facto relationship did not have significantly higher visuo-spatial memory scores than those who were single.

Notably, two previous studies have indicated that co-residence with a partner or adult children to be negatively associated with older adults' cognitive health when using Southern European samples (Bordone \& Weber, 2012; Mazzuco et al., 2017). Therefore, it could be postulated that there was selection bias in the current study's sample, which accounted for the unexpected finding for those in de facto relationships. Further, the sample distribution of the current study revealed the majority for those who were married to be aged between 27 and 62 and majority for those in a de facto relationship to be aged between 18 and 27. As such, this unpredicted result could be explained by differences in a relationship length, which could have restricted the cognitive stimulation from being in a relationship to buffer and delay cognitive ageing processes and hence contribute to higher cognitive reserve, for those who were in a de facto relationship (Feng et al., 2014; Stern, 2009). Regardless, the results suggest the implementation of proactive strategies to mitigate cognitive ageing for those who are single or in de facto relationships, as well as research evidence to evaluate their effectiveness.

Hedden and Gabrieli (2004) indicated that the risk of age-related cognitive changes increases as a function of age. Examination of means, from the current study also revealed younger married adults to have higher cognitive functioning than older married adults. For New Image scores, married individuals aged between 27 and 62, obtained scores that were significantly higher than those aged $62+$. These findings may give support to cognitive degradation occurring before the age of 65 (Salthouse, 2011). However, discussion of these results should be made with caution because of insufficient cases for analysis (Tabachnick \& Fidell, 2014).

The second hypothesis was not supported as there was no significant interaction effect for age and gender evident in the current study. This suggests that animal models may not be applicable to human cognition, as rodent studies have revealed different outcomes, finding significant age and sex differences on cognitive ageing (Benice \& Raber, 2009; Bernice et al., 2006). As previously mentioned, Carroll's (2015) study did not use an established scale with psychometric properties in the measurement of social networks, which was thought to confound results due to reported sex differences in expectations of social relationships (Liao \& Scholes, 2017). However, there was no significant covariate effect of engagement with social networks on age-associated cognitive decline, adding credence to Carroll's (2015) findings. Literature has also indicated that women have more positive exchanges with children, other family, and friends compared to men and these positive exchanges may be indicative of greater cognitive sti- 
mulation for women than men (Stafford et al., 2011). However, modern society may challenge these stereotypical gender representations. In light of the current study, it is plausible to consider the sample size as restricting the current study's ability to distinguish gender effects.

No significant interaction between age and type of measure was found, therefore, support for the generalised model of ageing was demonstrated. This could be reflective of insensitive instrumentation and as such a more sensitive test is suggested for future research to discriminate between generalised and modular cognitive ageing processes with age. Examination of the slope of the standardised comparison revealed the NINL_BR to be more sensitive to age-related changes than span. This finding is consistent with Gronholm-Nyman et al.'s (2009) and Traykov et al.'s (2007) findings. Miller's (1956) study of STM also concluded that span was $7 \pm 2$ digits, suggesting that the limit of memory was about seven familiar chunks. For the current study, each participant's mean digit span was within Miller's (1956) $7 \pm 2$ digits $(M=6.15, S D=1.85)$ and showed no significant span effect with age. Future replication may aim to implement different memory processes and instrumentation to clarify what happens inside the ageing brain, ensuring the most effective interventions are implemented for successful cognitive outcomes for the current ageing Australian population.

\subsection{Limitations and Future Research}

Interpretation of the above results for the current study should be considered with reference to the limitations. The current study's gender distribution was not representative of the Australian population. Therefore, a larger more representative sample may ensure that gender effects are distinguished, while establishing generality to the Australian population. However, the current study's gender distribution being overly representative of women compared to men is representative of other similar studies (Shadish et al., 2002). Further, insufficient cell sizes for the widowhood category and the inability to collapse cells into another marital status category restricted the study's ability to examine the impact of widowhood on cognitive ageing. As such, future studies could use alternative sampling techniques (e.g., direct random stratified sampling), making the ability to reach a larger widowed community more achievable.

\subsection{Implications}

The principle finding of the present study was that those participants who were married obtained significantly higher visuo-spatial memory scores than those who were in a de facto relationship or single. The results from the current study add validation to existing studies, which have found being married to be a protective factor against age-associated cognitive decline. Broadly, the current study's findings contribute to the notion that being socially engaged buffers against cognitive ageing. Targeted interventions for client groups who are not in a marital relationship, to increase cognitive reserve and consequently reduce the 
risk of unwarranted cognitive ageing, are suggested. However, the need for further examination into the effects of marital status on age-associated cognitive decline is warranted. As such, it is suggested that future studies examine the differences in cognitive stimulation and quality of relationships between those who are married and in a de facto relationship. This would enable the development of psychologically tailored diagnostic tools and treatments that add new cognitive and social activities to an individual's lifestyle, to increase awareness on cognitive reserve factors and prevent unwarranted cognitive decline. This may have long-term benefits by extending the living status of ageing adults to the home over institutionalised care, decreasing pressure on individual and societal resources.

The study's findings also supported the generalised model of cognitive degradation. This has implications for a preventive medicine approach to cognitive deterioration. If decline is generalised, a raft of cognitive interventions rather than specific targeted interventions, to increase cognitive reserve, is suggested. It would be recommended that future studies focus on other measures to examine cognitive dissociation processes, ensuring the most effective interventions are implemented for successful cognitive outcomes for the current ageing Australian population. In light of the above, the need to better understand the impact of age, gender, and marital status to buffer and delay age-associated cognitive decline remains a primary public health and research goal.

\section{Declarations}

The data was only accessible by the researcher and is stored with a password protected file for five years at Bond University, in accordance with the guidelines set out by Bond University Human Research Ethics Committee (BUHREC). None of the experiments were preregistered.

\section{Ethical Approval and Informed Consent}

All procedures performed in studies involving human participants were in accordance with the ethical standards of BUHREC and conducted in alignment with the National Statement (2007). Participants who voluntarily selected that they understood informed consent were able to proceed in the study, inferring participation.

\section{Acknowledgements}

I would firstly like to thank Dr. Mark Bahr for his ongoing support, patience, gentle guidance, and calming nature throughout. It was an honour to work with someone of such high calibre. Thank you for taking me under your "wing".

I would also like to extend my special thanks to my parents for their continual support and love. Thank you for always believing in me and for your unfailing commitment. I am so blessed to have you as my parents. To my grandmother, June, thank you for your wisdom, compassion, and continued support in my 
academic goals. I would also like to thank my sister, Emma, for her thoughtfulness throughout the year. To Jesus, thank you for your never-ending kindness and allowing me to have this study opportunity at Bond University.

To my roommate, Cat, thank you for making my transition to Bond feel like home. I will never forget the memories we shared together and how you taught me to see perspective in the midst of the stress. I would also like to thank Kezia, Ut, Dan, and Maya for their encouragement throughout.

Thank you also to Cameron for your help in refining my academic writing.

To Shawn, hopefully there will be more walls to paint in the future. Thank you for your friendship, continual help with formatting tables, morning swims, and humour.

\section{Funding}

No funding was received for this project.

\section{Conflicts of Interest}

On behalf of all authors, the corresponding author states that there is no conflict of interest.

\section{References}

Aartsen, M. J., Van Tilburg, T., Smits, C. H., Comijs, H. C., \& Knipscheer, K. C. (2005). Does Widowhood Affect Memory Performance of Older Persons? Psychological Medicine, 35, 217-226. https://doi.org/10.1017/S0033291704002831

Baltes, P. B., \& Baltes, M. M. (1990). Psychological Perspectives on Successful Ageing: The Model of Selective Optimization with Compensation. In P. B. Baltes, \& M. M. Baltes (Eds.), Successful Ageing: Perspectives from the Behavioural Sciences (pp. 1-34). New York: Cambridge University Press. https://doi.org/10.1017/CBO9780511665684

Benice, T. S., \& Raber, J. (2009). Testosterone and Dihydrotestosterone Differentially Improve Cognition in Aged Female Mice. Learning Memory, 16, 479-485. https://doi.org/10.1101/lm.1428209

Berg, L. (1988). Clinical Dementia Rating (CDR). Psychopharmacol Bulletin, 24, 637-639. https://www.ncbi.nlm.nih.gov/pubmed/3249765

Bernice, T. S., Rizk, A., Kohama, S., Pfankuch, T., \& Raber, J. (2006). Sex-Differences in Age-Related Cognitive Decline in C57BL/6J Mice Associated with Increased Brain Microtubule-Associated Protein 2 and Synaptophysin Immunoreactivity. Neuroscience, 137, 413-423. https://doi.org/10.1016/j.neuroscience.2005.08.029

Berteau-Pavy, F., Park, B., \& Raber, J. (2007) Effects of Sex and APOE e4 on Object Recognition and Spatial Navigation in the Elderly. Neuroscience, 147, 6-17. https://doi.org/10.1016/j.neuroscience.2007.03.005

Bordone, V., \& Weber, D. (2012). Number of Children and Cognitive Abilities in Later Life. Vienna Yearbook of Population Research, 10, 95-126.

https://doi.org/10.1553/populationyearbook2012s95

Brown, T. A., Chorpita, B. F., Korotitsch, W., \& Barlow, D. (1997). Psychometric Properties of the Depression Anxiety Stress Scales (DASS) in Clinical Samples. Behaviour Research Therapy, 35, 79-89. https://www.ncbi.nlm.nih.gov/pubmed/9009048 https://doi.org/10.1016/S0005-7967(96)00068-X 
Byers, A. L., Yaffe, K., Covinsky, K. E., Friedman, M. B., \& Bruce, M. L. (2010). High Occurrence of Mood and Anxiety Disorders among Older Adults: The National Comorbidity Survey Replication. Archives of General Psychiatry, 67, 489-496.

https://doi.org/10.1001/archgenpsychiatry.2010.35

Caroll, J. (2015). Conjugal Loss and Cognitive Decline in an Ageing Population (Unpublished Master's Thesis). Gold Coast: Bond University.

Carroll, J., \& Bahr, M. (2015). Bond Novel Image Novel Location-Revised. Unpublished Manuscript.

Centres for Disease Control and Prevention and the Alzheimer's Association (n.d.). Promoting Health and Independence for an Ageing Population at a Glance.

https://www.cdc.gov/chronicdisease/resources/publications/aag/alzheimers.htm

Charles, S. T., \& Carstensen, L. L. (2010). Social and Emotional Ageing. Annual Review of Psychology, 61, 383-409. https://doi.org/10.1146/annurev.psych.093008.100448

Cornoldi, C., \& Vecchi, T. (2003). Visuo-Spatial Working Memory and Individual Differences. Hove: Psychology Press. https://doi.org/10.4324/9780203641583

Cornwell, E. Y., \& Waite, L. J. (2009). Social Disconnectedness, Perceived Isolation, and Health among Older Adults. Journal of Health and Social Behavior, 50, 31-48. https://doi.org/10.1177/002214650905000103

Coyle, J. T. (2003). Use It or Lose It-Do Effortful Mental Activities Protect against Dementia? The New England Journal of Medicine, 348, 2489-2490.

https://doi.org/10.1056/NEJMp030051

Craik, F. I. M., Bialystok, E., \& Freedman, M. (2010). Delaying the Onset of Alzheimer Disease. Neurology, 75, 1726-1729. https://doi.org/10.1212/WNL.0b013e3181fc2a1c

Crawford, J. R., \& Henry, J. D. (2003). The Depression Anxiety Stress Scales (DASS): Normative Data and Latent Structure in a Large Non-Clinical Sample. British Journal of Clinical Psychology, 42, 111-131. https://doi.org/10.1348/014466503321903544

Crawford, J. R., Cayley, C., Lovibond, P. F., Wilson, P. H., \& Hartley, C. (2011). Percentile Norms and Accompanying Interval Estimates from an Australian General Adult Population Sample for Self-Report Mood Scales (BAI, BDI, CRSD, CESD, DASS, DASS-21, STAI-X, STAI-Y, SRDS, and SRAS). Australian Psychologist, 46, 3-14. https://doi.org/10.1111/j.1742-9544.2010.00003.X

Crook, T. H., Youngjohn, J. R., Larrabee, G. J., \& Salama, M. (1992). Ageing and Everyday Memory. Neuropsychology, 6, 123-136. https://doi.org/10.1037/0894-4105.6.2.123

Crooks, V. C., Lubben, J., Petitti, D. B., Little, D., \& Chiu, V. (2008). Social Network, Cognitive Function, and Dementia Incidence among Elderly Women. American Journal of Public Health, 98, 1221-1227. https://doi.org/10.2105/AJPH.2007.115923

Deary, I. J., Corley, J., Gow, A. J., Harris, S. E., Houlihan, L. M., Marioni, R. E., \& Starr, J. M. (2009). Age-Associated Cognitive Decline. British Medical Bulletin, 92, 135-152. https://doi.org/10.1093/bmb/ldp033

Delaloye, C., Moy, G., Baudois, S., De Bilbao, F., Remund, C. D., Hofer, F., Giannakopoulos, P. et al. (2009). The Contribution of Ageing to the Understanding of the Dimensionality of Executive Functions. Archives of Gerontology and Geriatrics, 49, e51-e59. https://doi.org/10.1016/j.archger.2008.08.011

Diener, E. D., Emmons, R. A., Larsen, R. J., \& Griffin, S. (1985). The Satisfaction with Life Scale. Journal of Personality Assessment, 49, 71-75.

https://doi.org/10.1207/s15327752jpa4901_13

Elovainio, M., Sommerlad, A., Hakulinen, C., Pulkki-Råback, L., Virtanen, M., Kivimäki, M., \& Singh-Manoux, A. (2018). Structural Social Relations and Cognitive Ageing Tra- 
jectories: Evidence from the Whitehall II Cohort Study. International Journal of Epidemiology, 47, 701-708. https://doi.org/10.1093/ije/dyx209

Ertel, K. A., Glymour, M. M., \& Berkman, L. F. (2008). Effects of Social Integration on Preserving Memory Function in a Nationally Representative US Elderly Population. American Journal of Public Health, 98, 1215-1220. https://doi.org/10.2105/AJPH.2007.113654

Faul, F., Erdfelder, E., Lang, A. G., \& Buchner, A. (2007). GPower 3: A Flexible Statistical Power Analysis Program for the Social, Behavioural, and Biomedical Sciences. Behaviour Research Methods, 39, 175-191. https://doi.org/10.3758/BF03193146

Feng, L., Ng, X. T., Yap, P., Li, J., Lee, T. S., Hakansson, K., Kua, E. H., \& Ng, T. (2014). Marital Status and Cognitive Impairment among Community-Dwelling Chinese Older Adults: The Role of Gender and Social Engagement. Dementia and Geriatric Cognitive Disorders Extra, 4, 375-384. https://doi.org/10.1159/000358584

Folstein, M. F., Folstein, S. E., \& McHugh, P. R. (1975). Mini-Mental State: A Practical Method for Grading the Cognitive State of Patients for the Clinician. Journal of Psychiatric Research, 12, 189-198. https://doi.org/10.1016/0022-3956(75)90026-6

Franzen, M. D., Robbins, D. E., \& Sawicki, R. F. (1989). Critical Issues in Neuropsychology-Reliability and Validity in Neuropsychological Assessment. New York: Plenum Press.

Fratiglioni, L., \& Wang, H. (2007). Brain Reserve Hypothesis in Dementia. Journal of Alzheimer's Disease: JAD, 12, 11-22. https://doi.org/10.3233/JAD-2007-12103

Gaymu, J., Delbès, C., Springer, S., Binet, A., Dèsesquelles, A., Kalogirou, S., \& Ziegler, U. (2006). Determinants of the Living Arrangements Old Older People in Europe. European Journal of Population, 22, 241-62. https://doi.org/10.1007/s10680-006-9004-7

Gloster, A. T., Rhoades, H. M., Novy, D., Klotsche, J., Senior, A., Kunik, M., Wilson, N., \& Stanley, M. A. (2008). Psychometric Properties of the Depression Anxiety Stress Scale-21 in Older Primary Care Patients. Journal of Affective Disorders, 110, 248-259. https://doi.org/10.1016/j.jad.2008.01.023

Gray, J., Kim, J., Ciesla, J. R., \& Yao, P. (2016). Rasch Analysis of the Lubben Social Network Scale-6 (LSNS-6). Journal of Applied Gerontology, 35, 508-528. https://doi.org/10.1177/0733464814560468

Gronholm-Nyman, P., Rinne, J. O., \& Laine, M. (2009). Learning and Forgetting New Names and Objects in MCI and AD. Neuropsychologia, 48, 1079-1088. https://doi.org/10.1016/j.neuropsychologia.2009.12.008

Håkansson, K., Rovio, S., Helkala, E., Vilska, A., Winblad, B., Soininen, H., \& Kivipelto, M. (2009). Association between Mid-Life Marital Status and Cognitive Function in Later Life: Population Based Cohort Study. BMJ, 339, 1-8.

https://doi.org/10.1136/bmj.b2462

Haley, G. E., Berteau-Pavy, F., Park, B., \& Raber, J. (2010). Effects of $\varepsilon 4$ on Object Recognition in the Non-Demented Elderly. Current Ageing Science, 3, 127-137. https://www.ncbi.nlm.nih.gov/pmc/articles/PMC4849126 https://doi.org/10.2174/1874609811003020127

Harada, C. N., Natelson Love, M. D., \& Triebel, K. L. (2013). Normal Cognitive Ageing. Clinics in Geriatric Medicine, 29, 737-752. https://doi.org/10.1016/j.cger.2013.07.002

Hardy, J. J. (2002). The Amyloid Hypothesis of Alzheimer's Disease: Progress and Problems on the Road to Therapeutics. Science, 297, 353-356.

https://doi.org/10.1126/science.1072994

Harrison, A. G., Rosenblum, Y., \& Currie, S. (2010). Examining Unusual Digit Span Per- 
formance in a Population of Postsecondary Students Assessed for Academic Difficulties. Assessment, 17, 283-293. https://doi.org/10.1177/1073191109348590

Hayley, G. E., Berteau-Pavy, F., Berteau-Pavy, D., \& Raber, J. (2012). Novel Image-Novel Location Object Recognition Task Sensitive to Age-Related Cognitive Decline in Nondemented Elderly. AGE, 34, 1-10. https://doi.org/10.1007/s11357-010-9204-2

Hedden, T., \& Gabrieli, J. D. (2004). Insights into the Ageing Mind: A View from Cognitive Neuroscience. Nature Reviews Neuroscience, 5, 87-96.

https://doi.org/10.1038/nrn1323

Henry, J. D., \& Crawford, J. R. (2005). The Short-Form Version of the Depression Anxiety Stress Scales (DASS-21): Construct Validity and Normative Data in a Large Non-Clinical Sample. British Journal of Clinical Psychology, 44, 227-239. https://doi.org/10.1348/014466505X29657

Holden, H. M., \& Gilbert, P. E. (2012). Less Efficient Pattern Separation May Contribute to Age-Related Spatial Memory Deficits. Frontiers in Ageing Neuroscience, 4, 9. https://doi.org/10.3389/fnagi.2012.00009

Hort, J., Laczo, J., Vyhnalek, M., Bojar, M., Bures, J., \& Vicek, K. (2007). Spatial Navigation Deficit in Amnestic Mild Cognitive Impairment. Proceedings of the National Academy of Sciences of the United States of America, 104, 4042-4047. https://doi.org/10.1073/pnas.0611314104

Iachini, T., Iavarone, A., Senese, V., Ruotolo, F., \& Ruggiero, G. (2009). Visuospatial Memory in Healthy Elderly, AD and MCI: A Review. Current Ageing Science, 2, 43-59. https://doi.org/10.2174/1874609810902010043

International Wellbeing Group (2013). Personal Wellbeing Index: 5th Edition. Melbourne: Australian Centre on Quality of Life, Deakin University.

Jenkins, L., Myerson, J., Joerding, J. A., \& Hale, S. (2000). Converging Evidence That Visuospatial Cognition Is More Age-Sensitive than Verbal Cognition. Psychology and Ageing, 15, 157-175. https://doi.org/10.1037/0882-7974.15.1.157

Kremen, W. S., Lachman, M. E., Pruessner, J. C., Sliwinski, M., \& Wilson, R. S. (2012). Mechanisms of Age-Related Cognitive Change and Targets for Intervention: Social Interactions and Stress. The Journals of Gerontology, 67, 760-765. https://doi.org/10.1093/gerona/gls125

Lau, A. L. D., \& Cummins, R. A. (2005). Test-Retest Reliability of the Personal Wellbeing Index. Unpublished Research Report, Hong Kong: The Hong Kong Polytechnic University. https://doi.org/10.1037/t70751-000

Lau, A. L. D., Cummins, R. A., \& McPherson, W. (2005). An Investigation into the Cross-Cultural Equivalence of the Personal Wellbeing Index. Social Indicators Research, 72, 403-430. https://doi.org/10.1007/s11205-004-0561-Z

Lee, G. R., DeMaris, A., Bavin, S., \& Sullivan, R. (2001). Gender Differences in the Depressive Effect of Widowhood in Later Life. The Journals of Gerontology. Series B, Psychological Sciences and Social Sciences, 56, 56-61. https://doi.org/10.1093/geronb/56.1.S56

Levy, B. R. (2003). Mind Matters: Cognitive and Physical Effects of Ageing Self-Stereotypes. The Journals of Gerontology, Series B, Psychological Sciences and Social Sciences, 58, 203. https://doi.org/10.1093/geronb/58.4.P203

Lezak, M. D. (1983). Neuropsychological Assessment. Oxford: Oxford University Press.

Liao, J., \& Scholes, S. (2017). Association of Social Support and Cognitive Ageing Modified by Sex and Relationship Type: A Prospective Investigation in the English Longitudinal Study of Ageing. American Journal of Epidemiology, 186, 787-795. 
https://doi.org/10.1093/aje/kwx142

Lovibond, S. H., \& Lovibond, P. F. (1995). Manual for the Depression Anxiety Stress (2nd ed.). Sydney: Psychology Foundation. https://doi.org/10.1037/t01004-000

Lubben, J. E. (1988). Assessing Social Networks among Elderly Populations. Family \& Community Health, 11, 42-52. https://doi.org/10.1097/00003727-198811000-00008

Lubben, J. E., \& Gironda, M. W. (2003). Centrality of Social Ties to the Health and Well-Being of Older Adults. In B. Berkman, \& L. K. Harooytan (Eds.). Social Work and Health Care in an Ageing World (pp. 319-350). New York: Springer.

Lubben, J., Blozik, E., Gillmann, G., Iliffe, S., von Renteln Kruse, Beck, J. C., \& Stuck, A. E. (2006). Performance of an Abbreviated Version of the Lubben Social Network Scale among Three European Community-Dwelling Older Adult Populations. The Gerontologist, 46, 503-513. https://doi.org/10.1093/geront/46.4.503

Lucanin, J. D., Lucanin, D., \& Havelka, M. (2011). Cognitive Function and Depression in Elderly People. Psychological Topics, 20, 173-186.

https://www.researchgate.net/publication/289093499 Cognitive Function and Depres sion in Elderly People

Luo, L., \& Craik, F. (2008). Ageing and Memory: A Cognitive Approach. Canadian Journal of Psychiatry, 53, 346-353. https://doi.org/10.1177/070674370805300603

Mazzuco, S., Meggiolaro, S., Ongaro, F., \& Toffoluti, I. V. (2017). Living Arrangement and Cognitive Decline among Older People in Europe. Ageing and Society, 37, 1111-1133. https://doi.org/10.1017/S0144686X16000374

Meng, L., Liu, K., Liu, Y., Fang, X., \& Zhai, Y. (2018). The Mediating Role of Depression on the Relationship between Housebound Status and Cognitive Function among the Elderly in Rural Communities: A Cross-Sectional Study. Archives of Gerontology and Geriatrics, 78, 58-63. https://doi.org/10.1016/j.archger.2018.05.019

Miller, G. A. (1956). The Magical Number Seven, plus or minus Two: Some Limits on Our Capacity for Processing Information. Psychological Review, 63, 81-97. https://doi.org/10.1037/h0043158

Misajon, R., Pallant, J., \& Bliuc, A. M. (2016). Rasch Analysis of the Personal Wellbeing Index. Quality Life Research, 25, 2565-2569. https://doi.org/10.1007/s11136-016-1302-x

Mousavi-Nasab, S., Kormi-Nouri, R., Sundstrom, A., \& Nilsson, L. (2012). The Effects of Marital on Episodic and Semantic Memory in Healthy Middle-Aged and Old Individuals. Scandinavian Journal of Psychology, 53, 1-8. https://doi.org/10.1111/j.1467-9450.2011.00926.x

Myerson, J., Emery, L., White, D. A., \& Hale, S. (2003). Effects of Age, Domain, and Processing Demands on Memory Span: Evidence for Differential Decline. Ageing, Neuropsychology, and Cognition, 10, 20-27. https://doi.org/10.1076/anec.10.1.20.13454

Ng, F., Trauer, T., Dodd, S., Callaly, T., Campbell, S., \& Beck, M. (2007). The Validity of the 21-Item Version of the Depression Anxiety Stress Scales as a Routine Clinical Outcome Measure. Acta Neuropsychiatrica, 19, 304-310.

https://doi.org/10.1111/j.1601-5215.2007.00217.x

Norton, P. J. (2007). Depression Anxiety and Stress Scales (DASS-21): Psychometric Analysis across Four Racial Groups. Anxiety, Stress, \& Coping, 20, 253-265. https://doi.org/10.1080/10615800701309279

Ownby, R. L., Crocco, E., Acevedo, A., John, V., \& Loewenstein, D. (2006). Depression and Risk for Alzheimer Disease: Systematic Review, Meta-Analysis, and Metaregression Analysis. Archives of General Psychiatry, 63, 530-538.

https://doi.org/10.1001/archpsyc.63.5.530 
Perquin, M., Vaillant, M., Schuller, A. M., Pastore, J., Dartigues, J. F., Lair, M. L., \& Diederich, N. (2013). Lifelong Exposure to Multilingualism: New Evidence to Support Cognitive Reserve Hypothesis. PLoS ONE, 8, e62030. https://doi.org/10.1371/journal.pone.0062030

Raber, J. (2015). Novel Images and Novel Locations of Familiar Images as Sensitive Translational Cognitive Tests in Humans. Behavioural Brain Research, 285, 53-59. https://doi.org/10.1016/j.bbr.2015.01.046

Richardson, J. T. E. (2007). Measures of Short-Term Memory: A Historical Review. Cortex, 43, 635-650. https://doi.org/10.1016/S0010-9452(08)70493-3

Rizk-Jackson, A., Acevedo, S., Inman, D., Howieson, D., Benice, T., \& Raber, J. (2006). Effects of Sex on Object Recognition and Spatial Navigation in Humans. Behavioural Brain Research, 173, 181-190. https://doi.org/10.1016/j.bbr.2006.06.029

Ryan, L., \& Caltabiano, M. L. (2009). Development of a New Resilience Scale: The Resilience in Midlife Scale (RIM Scale). Asian Social Science, 5, 39-51. https://doi.org/10.5539/ass.v5n11p39

Salthouse, T. A. (1996). The Processing-Speed Theory of Adult Age Differences in Cognition. Psychological Review, 103, 403-428. https://doi.org/10.1037/0033-295X.103.3.403

Salthouse, T. A. (2009). When Does Age-Related Cognitive Decline Begin? Neurobiology of Ageing, 30, 507-514. https://doi.org/10.1016/j.neurobiolageing.2008.09.023

Salthouse, T. A. (2011). Consequences of Age-Related Cognitive Declines. The Annual Review of Psychology, 63, 5.1-5.26.

https://doi.org/10.1146/annurev-psych-120710-100328

Satz, P. (1993). Brain Reserve Capacity on Symptom Onset after Brain Injury: A Formulation and Review of Evidence for Threshold Theory. Neuropsychology, 7, 273-295. https://doi.org/10.1037/0894-4105.7.3.273

Shadish, W. R., Cook, T. D., \& Campbell, D. T. (2002). Experimental and Quasi-Experimental Designs for Generalized Causal Inference. Belmont, CA: Wads Worth Cengage Learning.

Sinclair, S. J., Siefert, C. J., Slavin-Mulford, J. M., Stein, M. B., Renna, M., \& Blais, M. A. (2012). Psychometric Evaluation and Normative Data for the Depression, Anxiety, and Stress Scales-21 (DASS-21) in a Nonclinical Sample of U.S Adults. Evaluation \& the Health Professions, 35, 259-279. https://doi.org/10.1177/0163278711424282

Stern, Y. (2009). Cognitive Reserve in Ageing and Alzheimer's Disease. The Lancet Neurology, 11, 1006-1012. https://doi.org/10.1016/S1474-4422(12)70191-6

Tabachnick, B. G., \& Fidell, L. S. (2014). Using Multivariate Statistics (6th ed.). Harlow: Pearson Education.

Tomyn, A. J., Fuller Tyszkiewicz, M. D., \& Cummins, R. A. (2013). The Personal Wellbeing Index: Psychometric Equivalence for Adults and School Children. Social Indicators Research, 110, 913-924. https://doi.org/10.1007/s11205-011-9964-9

Traykov, L., Raoux, N., Latour, F., Gallo, L., Hannon, O., Baudic, S., Rigaud, A.S. et al. (2007). Executive Functions Deficit in Mild Cognitive Impairment. Cognitive and Behavioral Neurology, 20, 219-224. https://doi.org/10.1097/WNN.0b013e31815e6254

Tschanz, J. T., Piercy, K., Corcoran, C. D., Fauth, E., Norton, M. C., Rabins, P. V., Tschanz, B. T., Deberard, M. S., Snyder, C., Smith, C., \& Luketsos, C. (2013). Caregiver Coping Strategies Predict Cognitive and Functional Decline in Dementia: The Cache County Dementia Progression Study. American Journal of Geriatric Psychiatry, 21, 57-66. https://doi.org/10.1016/j.jagp.2012.10.005

Turner, A. D., Capuano, A. W., Wilson, R. S., \& Barnes, L. L. (2015). Depressive Symp- 
toms and Cognitive Decline in Older African Americans: Two Scales and Their Factors. American Journal of Geriatric Psychiatry, 23, 568-578.

https://doi.org/10.1016/j.jagp.2014.08.003

Van Gelder, B. M., Tijhuis, M., Kalmijn, S., Giampaoli, S., Nissinen, A., \& Kromhout, D. (2006). Marital Status and Living Situation during a 5-Year Period Are Associated with a Subsequent 10-Year Cognitive Decline in Older Men: The FINE Study. Journal of Gerontology, 61, 213-219. https://doi.org/10.1093/geronb/61.4.P213

West, R. L., Thorn, R. M., \& Bagwell, D. K. (2003). Memory Performance and Beliefs as a Function of Goal Setting and Ageing. Psychology and Ageing, 18, 111-125. https://doi.org/10.1037/0882-7974.18.1.111

Wilson, R. S., Mendes De Leon, C. F., Bennett, D. A., Bienias, J. L., \& Evans, D. A. (2004). Depressive Symptoms and Cognitive Decline in a Community Population of Older Persons. Journal of Neurology, Neurosurgery, and Psychiatry, 75, 126.

https://search-proquest-com.ezproxy.bond.edu.au/docview/1781234204?OpenUrlRefId =info:xri/sid:primo\&accountid $=26503$

Wood, B. M., Nicholas, M. K., Blyth, F., Asghari, A., \& Gibson, S. (2010). The Utility of the Short Version of the Depression Anxiety Stress Scales (DASS-21) in Elderly Patients with Persistent Pain: Does Age Make a Difference? Pain Medicine, 11, 1780-1790. https://doi.org/10.1111/j.1526-4637.2010.01005.x

World Health Organisation (2018). Ageing and Health. http://www.who.int/news-room/fact-sheets/detail/ageing-and-health

Yates, J. A., Clare, L., \& Woods, R. T. (2017). "You've Got a Friend in Me": Can Social Networks Mediate the Relationship between Mood and MCI? BMC Geriatrics, 17, 1-7. https://doi.org/10.1186/s12877-017-0542-0 


\section{Appendix A}

Table A1. Chi square test for gender distribution of the current study's sample.

\begin{tabular}{|c|c|c|c|}
\hline \multicolumn{4}{|c|}{ Chi-Square Test Frequencies } \\
\hline \multicolumn{4}{|c|}{ gender dichotmous 0 female } \\
\hline \multicolumn{2}{|c|}{ Observed N } & Expected N & Residual \\
\hline Female & 79 & 62.5 & 16.5 \\
\hline Male & 46 & 62.5 & -16.5 \\
\hline Total & 125 & & \\
\hline \multicolumn{2}{|c|}{ Test Statistics } & \multicolumn{2}{|c|}{ gender dichotmous 0 female } \\
\hline \multicolumn{2}{|c|}{ Chi-Square } & \multicolumn{2}{|c|}{$8.712^{\mathrm{a}}$} \\
\hline \multicolumn{2}{|c|}{ df } & \multicolumn{2}{|c|}{1} \\
\hline \multicolumn{2}{|c|}{ Asymp. Sig. } & \multicolumn{2}{|c|}{0.003} \\
\hline
\end{tabular}

${ }^{a} 0$ cells $(0.0 \%)$ have expected frequencies less than 5 . The minimum expected cell frequency is 62.5 .

Table A2. Missing values analysis for all independent and dependent variables.

\begin{tabular}{|c|c|c|c|c|c|c|c|}
\hline \multicolumn{8}{|l|}{ MVA } \\
\hline \multicolumn{8}{|c|}{ Univariate Statistics } \\
\hline & \multirow{2}{*}{$\mathrm{N}$} & \multirow{2}{*}{ Mean } & \multirow{2}{*}{$\begin{array}{c}\text { Std. } \\
\text { Deviation }\end{array}$} & \multicolumn{2}{|c|}{ Missing } & \multicolumn{2}{|c|}{ No. of Extremes } \\
\hline & & & & Count & Percent & Low & High \\
\hline NL_prop & 126 & 0.0109 & 0.04189 & 0 & 0.0 & & \\
\hline NI_prop & 126 & 0.6627 & 0.19253 & 0 & 0.0 & 2 & 0 \\
\hline NC_prop & 126 & 0.4722 & 0.18634 & 0 & 0.0 & 0 & 1 \\
\hline NINL_prop & 126 & 0.3819 & 0.08971 & 0 & 0.0 & 1 & 0 \\
\hline mspan & 126 & 6.1786 & 1.74959 & 0 & 0.0 & 1 & 10 \\
\hline DASST & 125 & 12.6480 & 10.26681 & 1 & 0.8 & 0 & 6 \\
\hline resilience_tot & 125 & 61.4880 & 10.78501 & 1 & 0.8 & 3 & 3 \\
\hline Pwitot & 121 & 35.9917 & 14.55421 & 5 & 4.0 & 0 & 0 \\
\hline lsnstot & 126 & 19.1587 & 5.58342 & 0 & 0.0 & 0 & 0 \\
\hline gender & 125 & & & 1 & 0.8 & & \\
\hline Married & 121 & & & 5 & 4.0 & & \\
\hline trichage & 125 & & & 1 & 0.8 & & \\
\hline
\end{tabular}

a. Number of cases outside the range $\left(\mathrm{Q} 1-1.5{ }^{*} \mathrm{IQR}, \mathrm{Q} 3+1.5{ }^{*} \mathrm{IQR}\right)$. b. . Indicates that the inter-quartile range (IQR) is zero.

1) Scatterplot of each dependent variable and each covariate for the MANCOVA analysis 


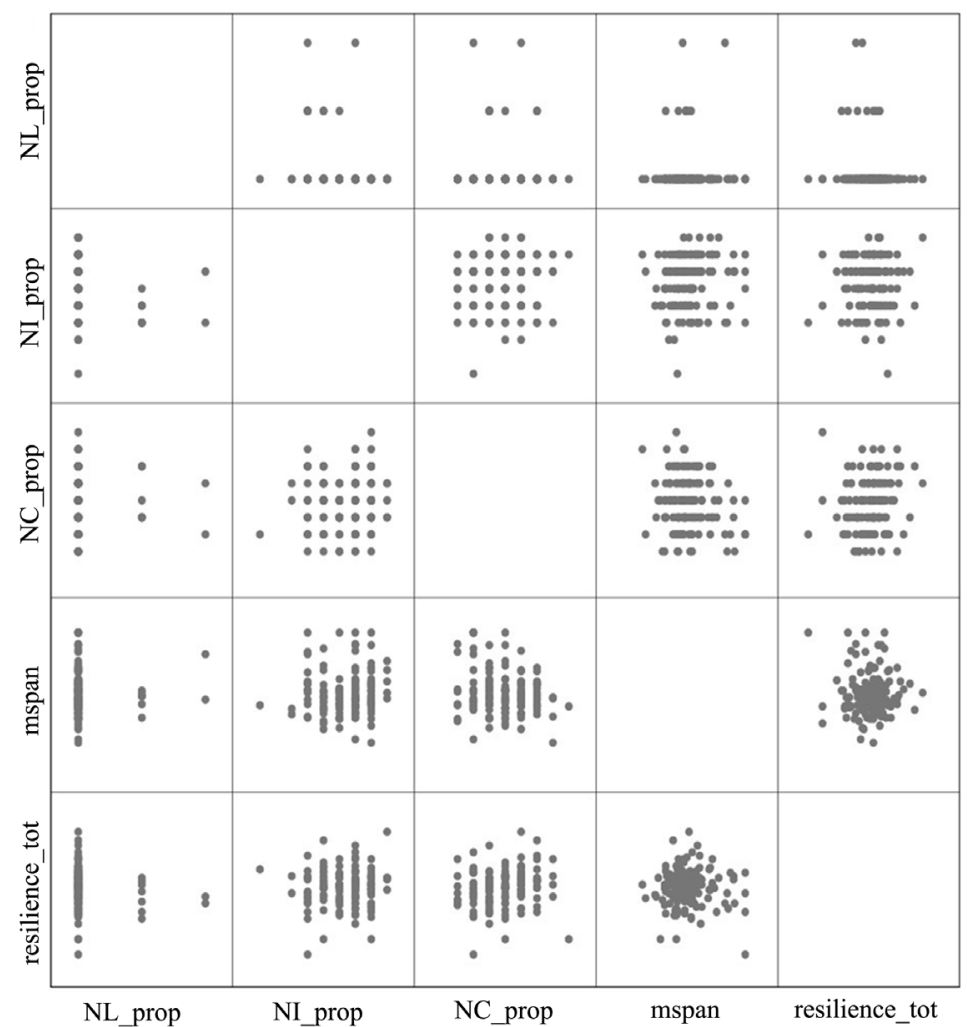

Figure A1.1. Scatterplot of each dependent variable and each covariate for the MANCOVA analysis.

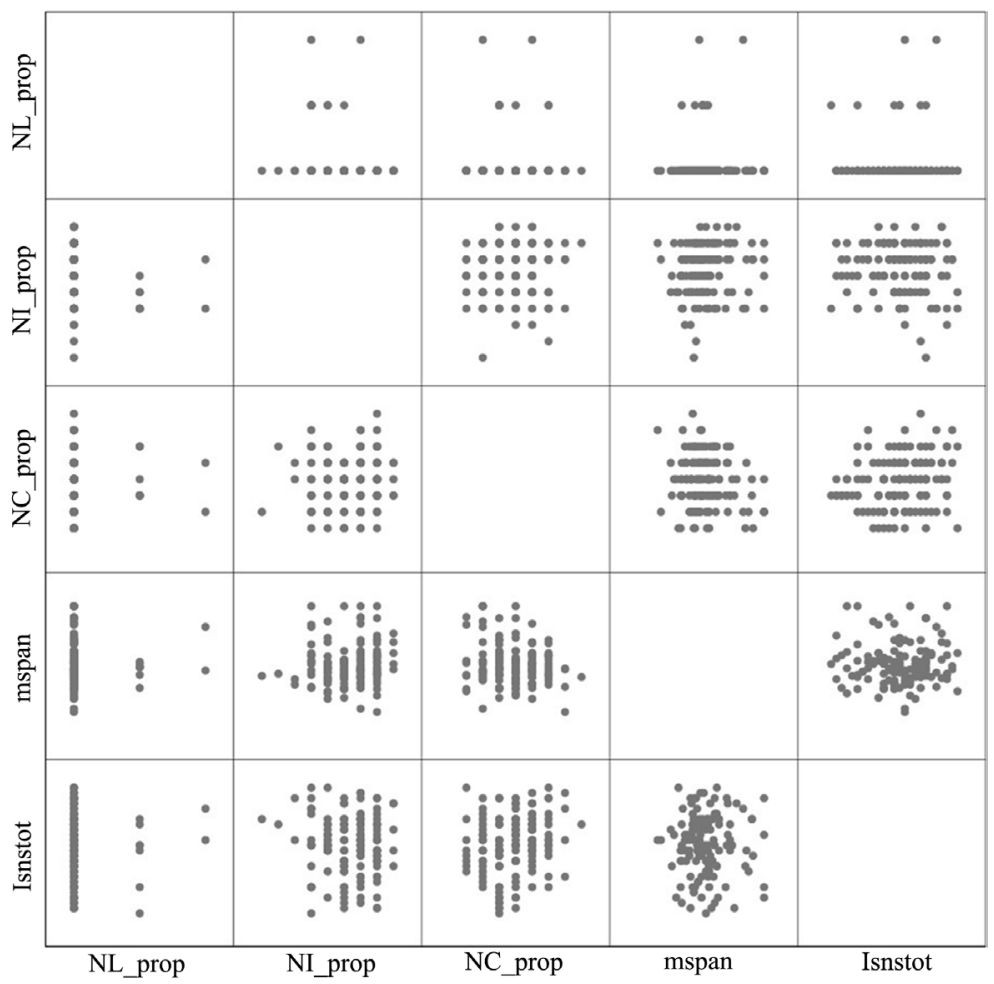

Figure A1.2. Scatterplot of each dependent variable and each covariate for the MANCOVA analysis. 


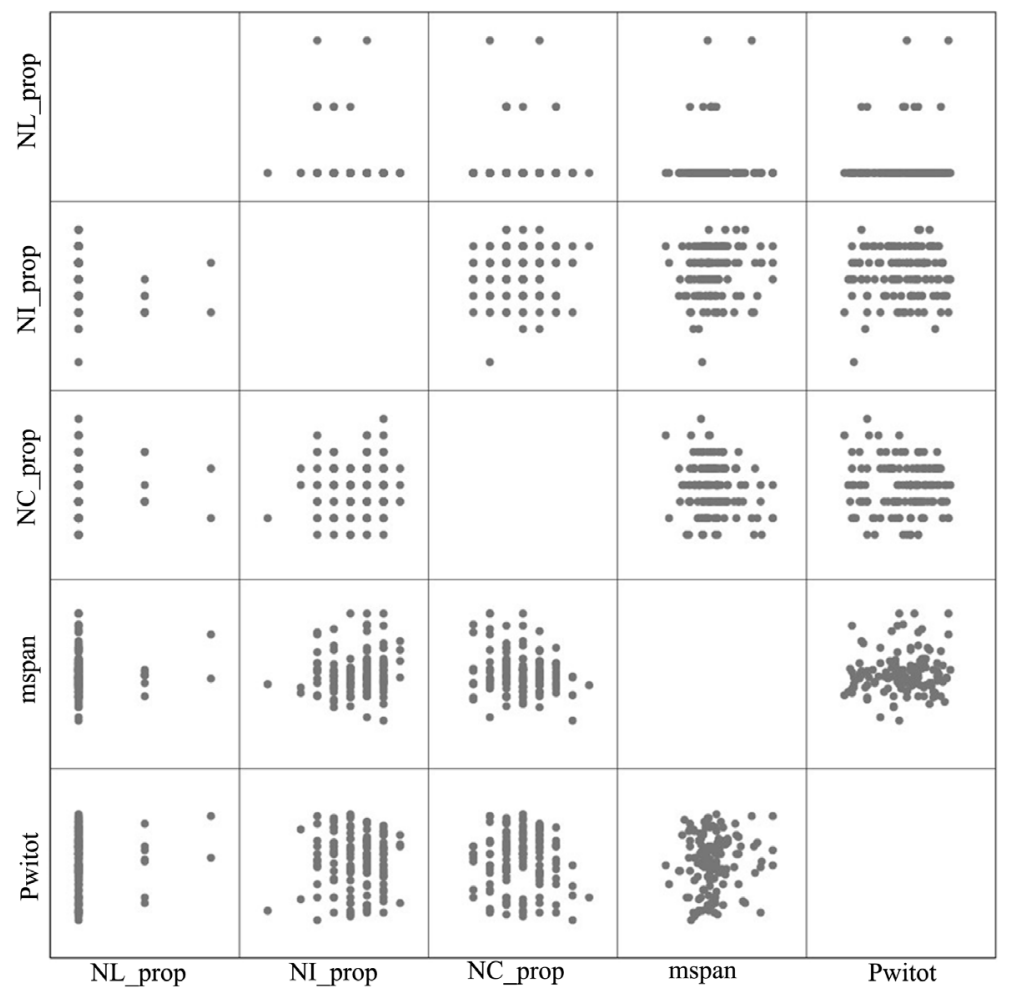

Figure A1.3. Scatterplot of each dependent variable and each covariate for the MANCOVA analysis.

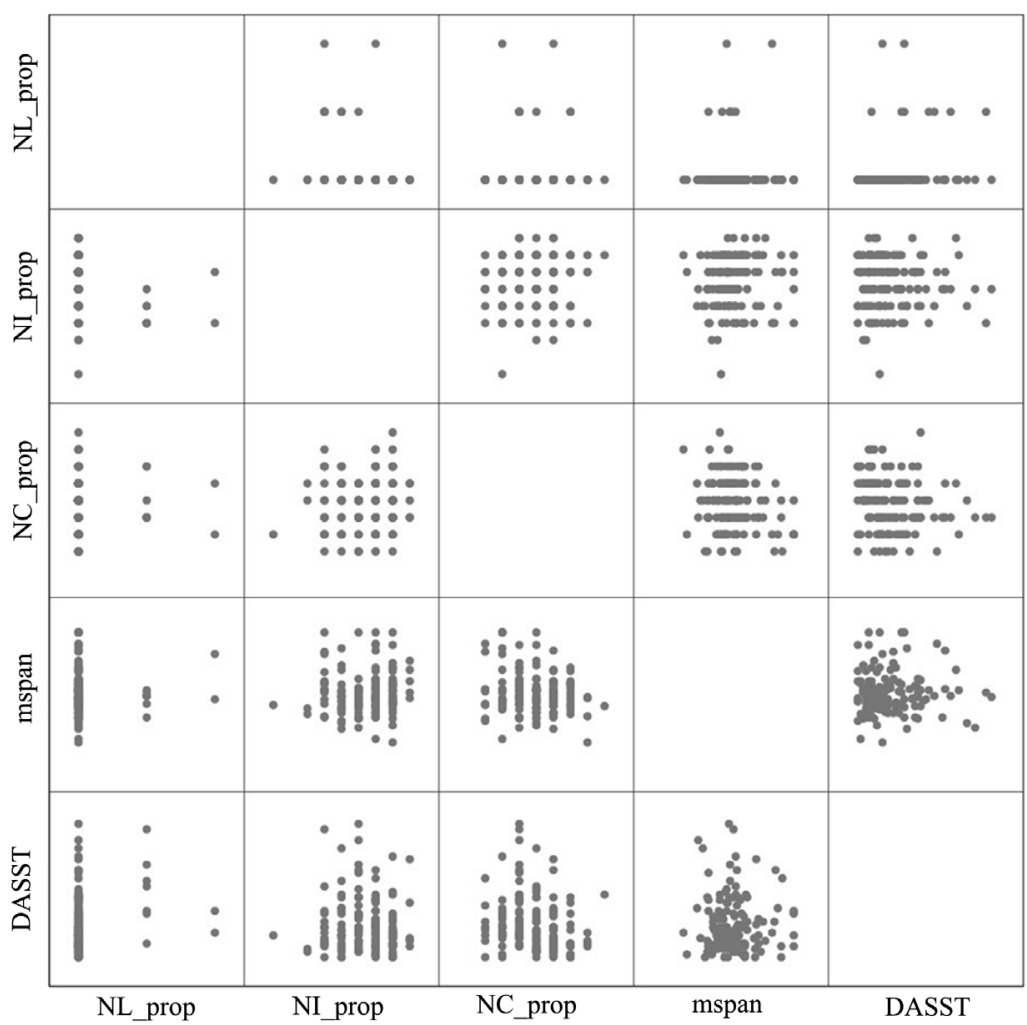

Figure A1.4. Scatterplot of each dependent variable and each covariate for the MANCOVA analysis. 


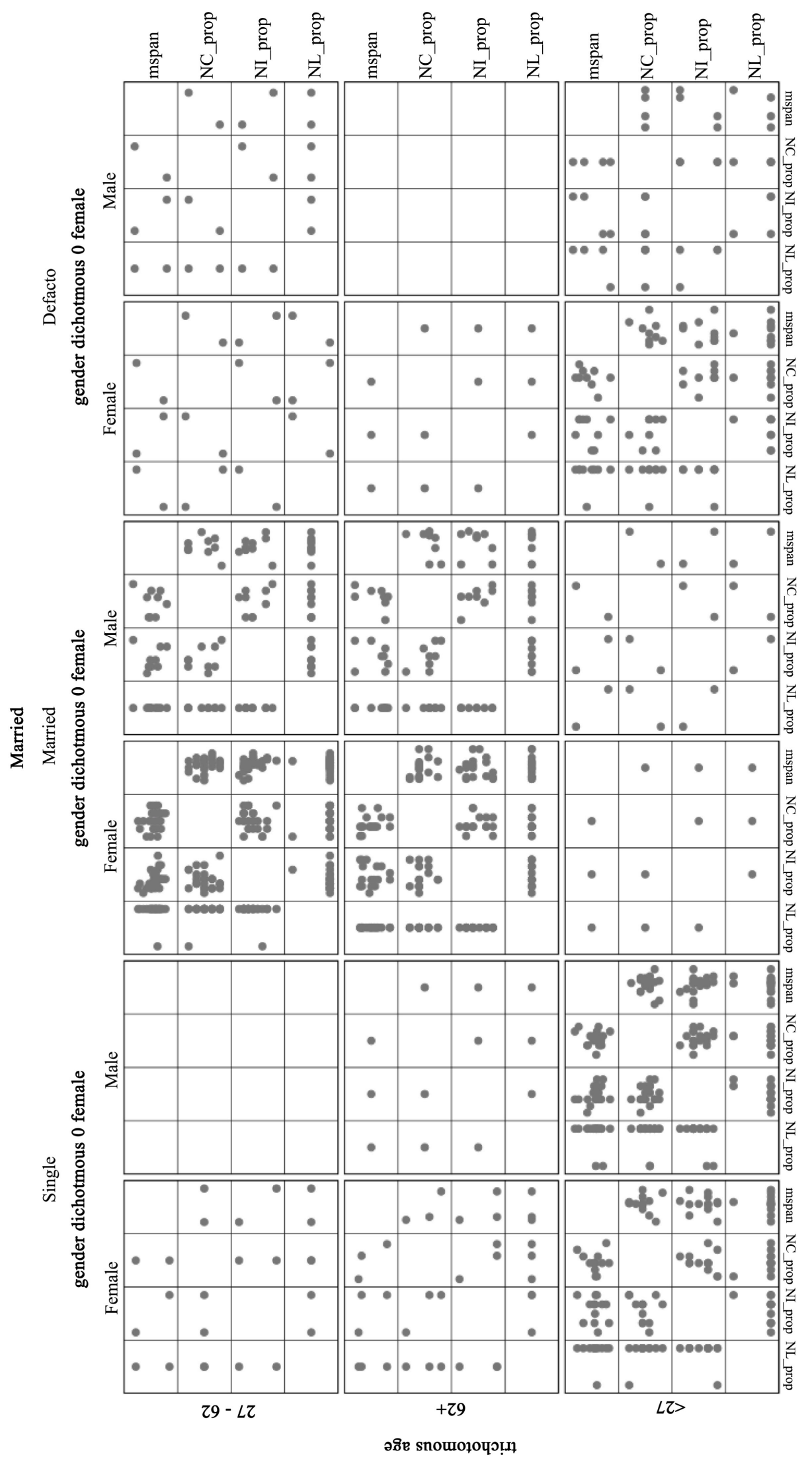

Figure A1.5. Scatterplot of each dependent variable and each covariate for the MANCOVA analysis. 


\section{2) Homoscedasticity assumption check}

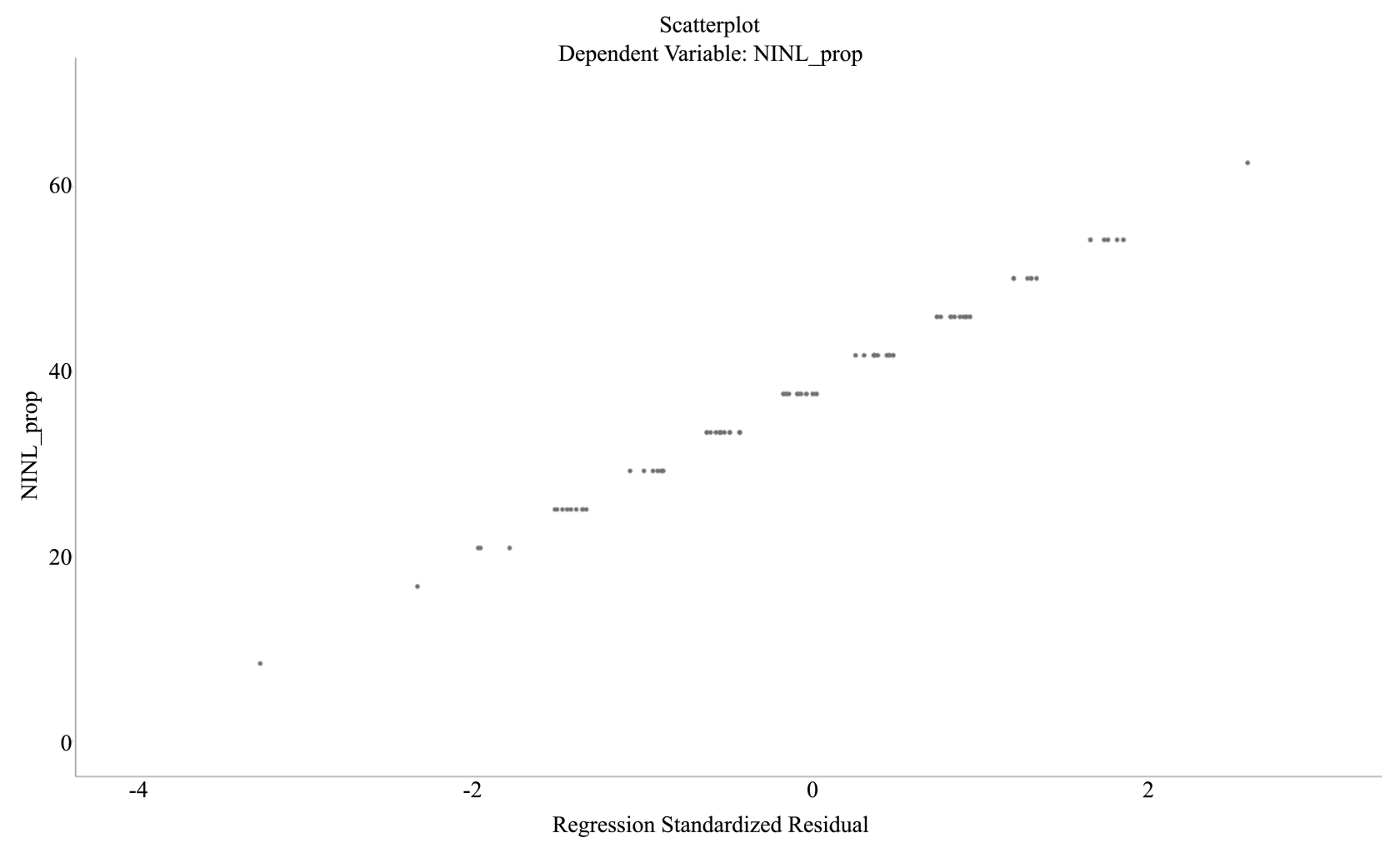

Figure A2.1. Homoscedasticity assumption check.

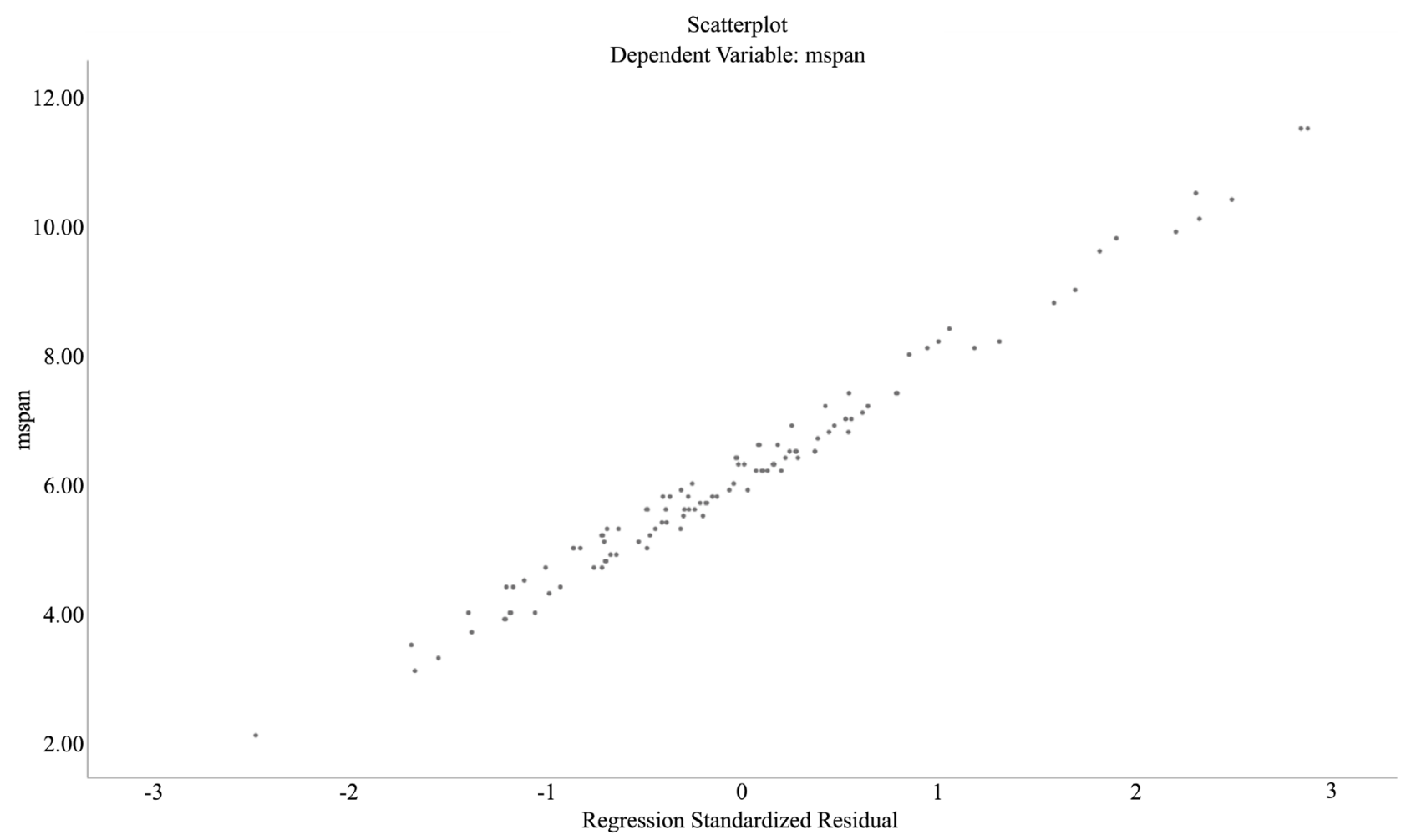

Figure A2.2. Homoscedasticity assumption check. 
3) Histograms for covariates and dependent variables

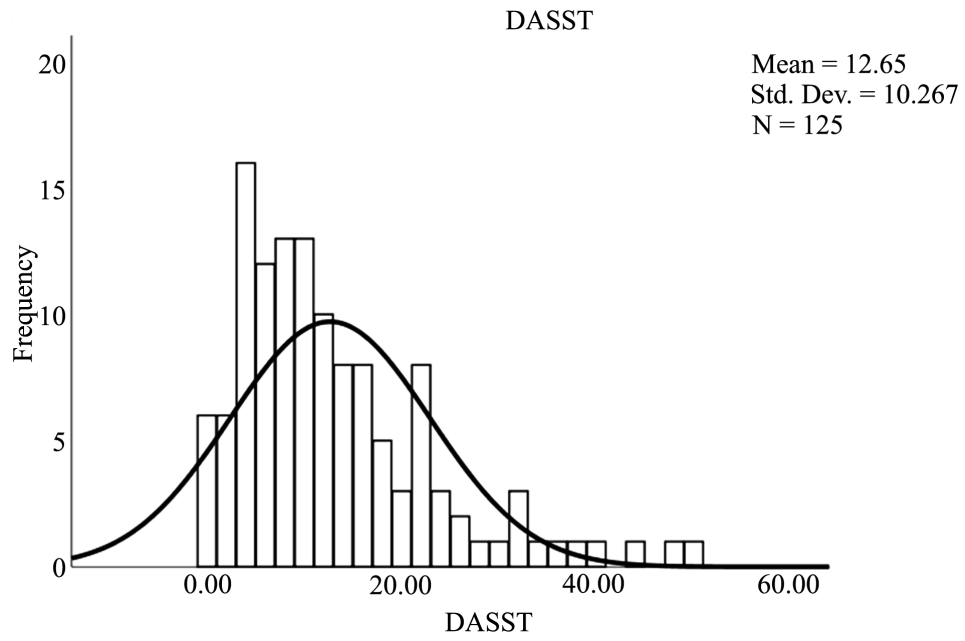

Figure A3.1. Histograms for covariates and dependent variables.

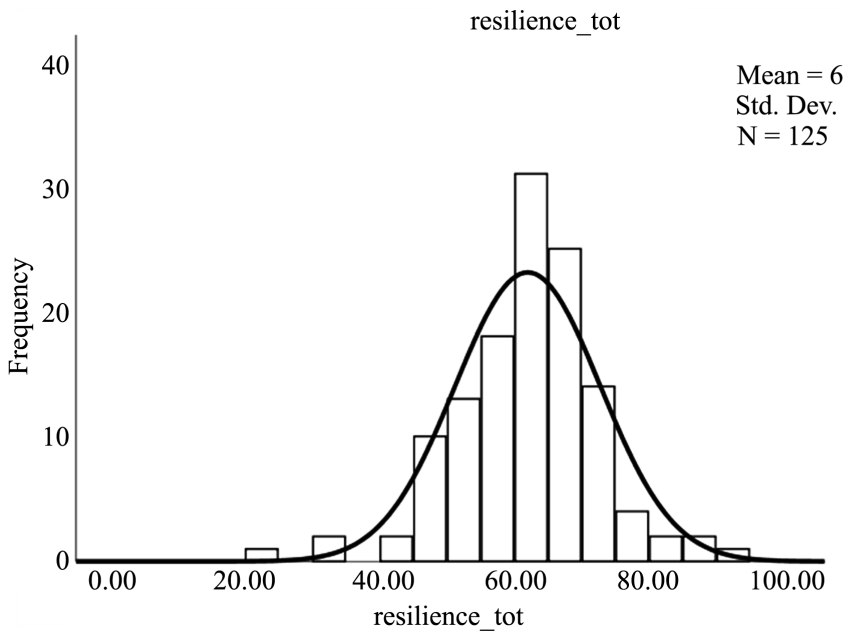

Figure A3.2. Histograms for covariates and dependent variables.

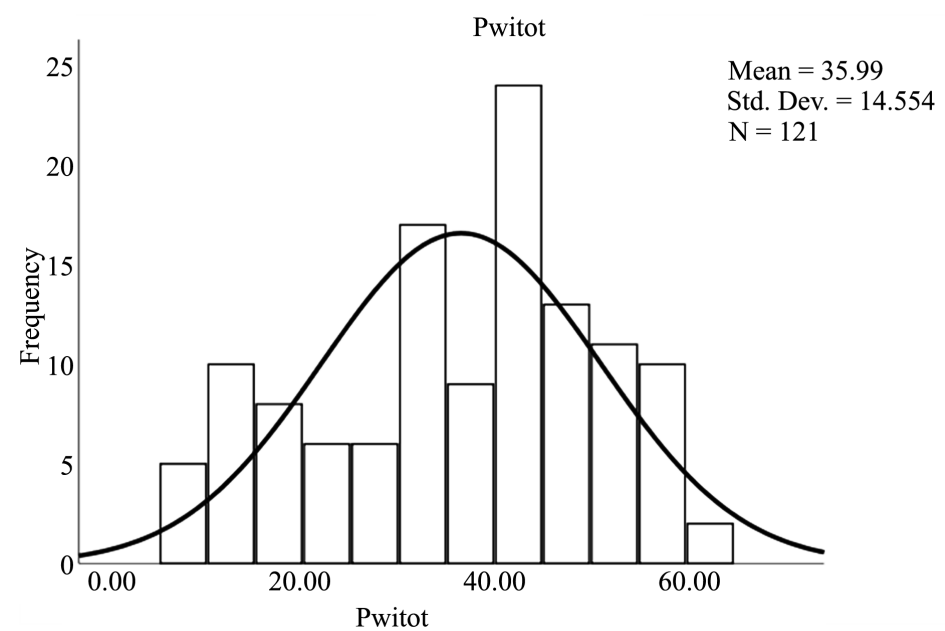

Figure A3.3. Histograms for covariates and dependent variables. 


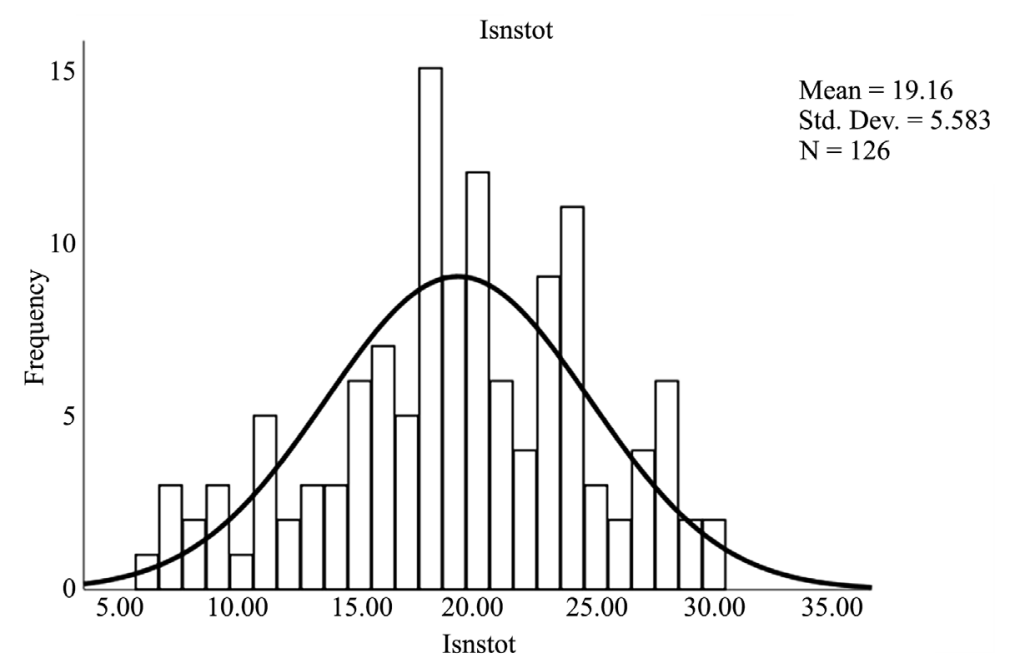

Figure A3.4. Histograms for covariates and dependent variables.

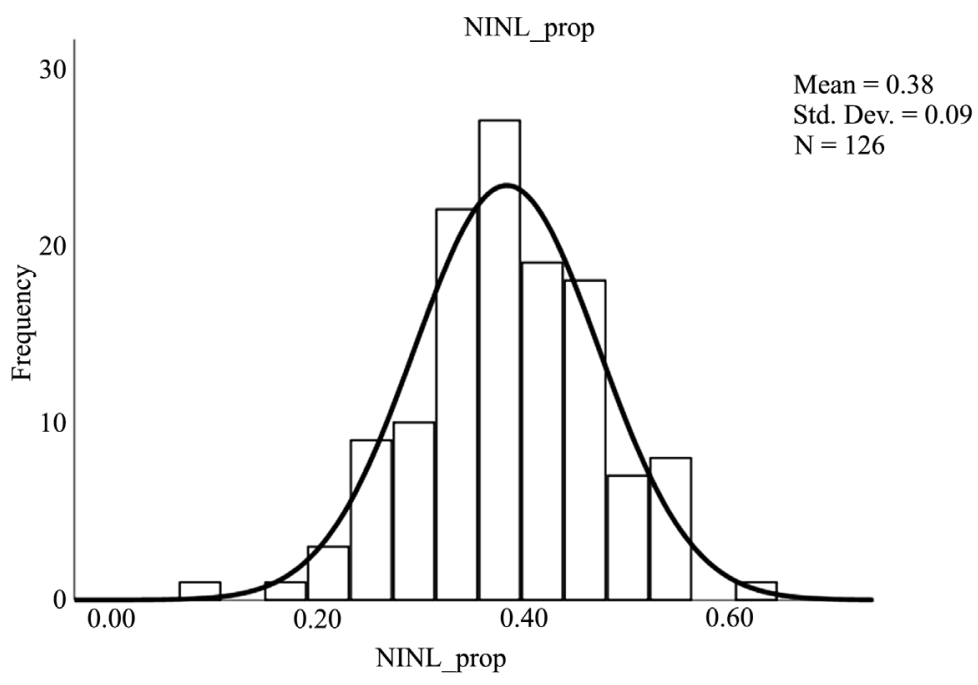

Figure A3.5. Histograms for covariates and dependent variables.

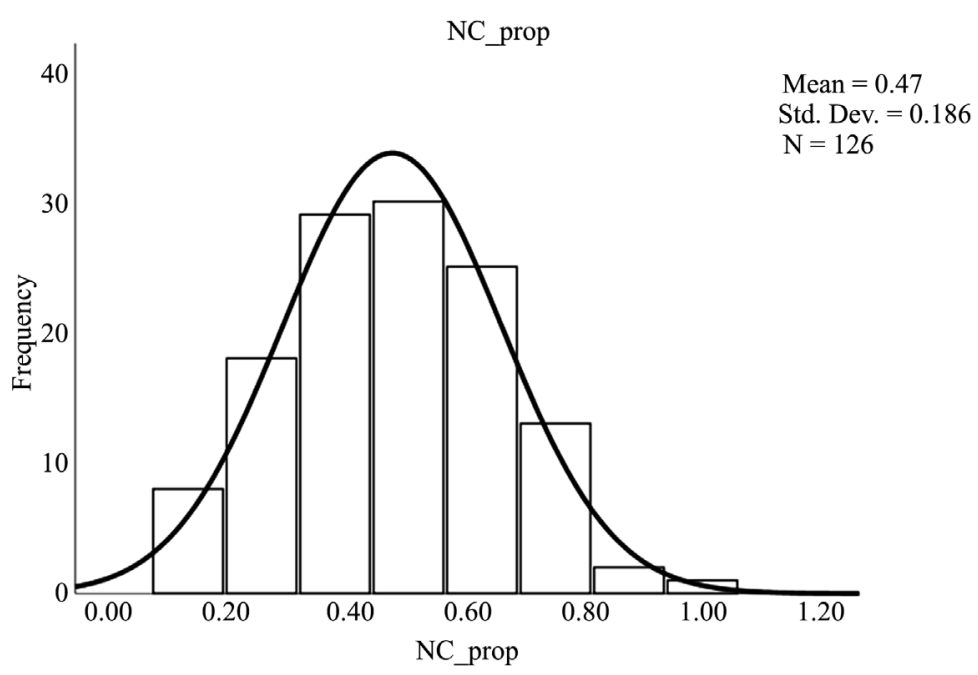

Figure A3.6. Histograms for covariates and dependent variables. 


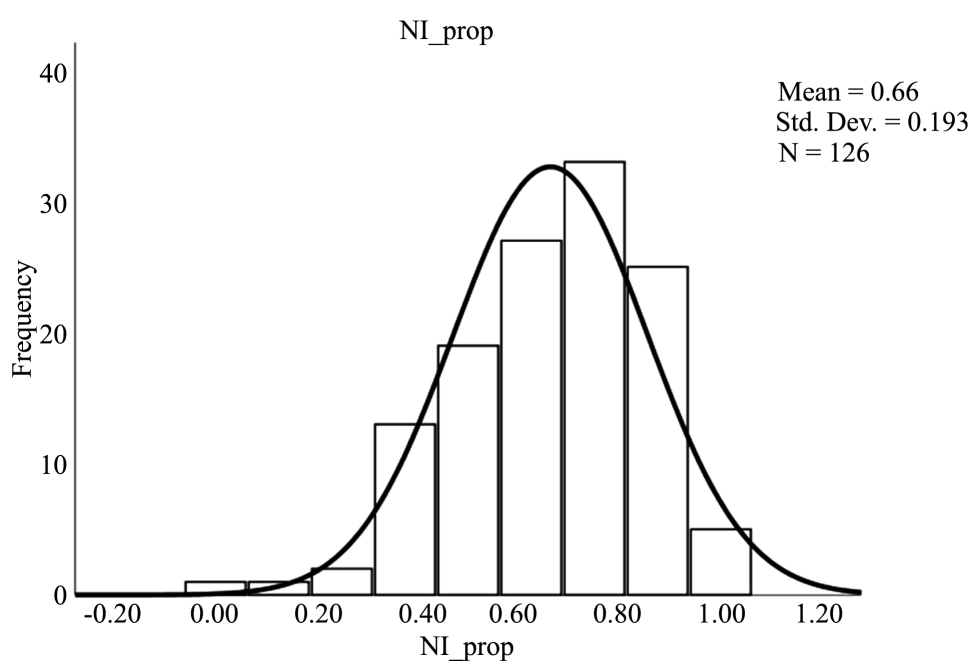

Figure A3.7. Histograms for covariates and dependent variables.

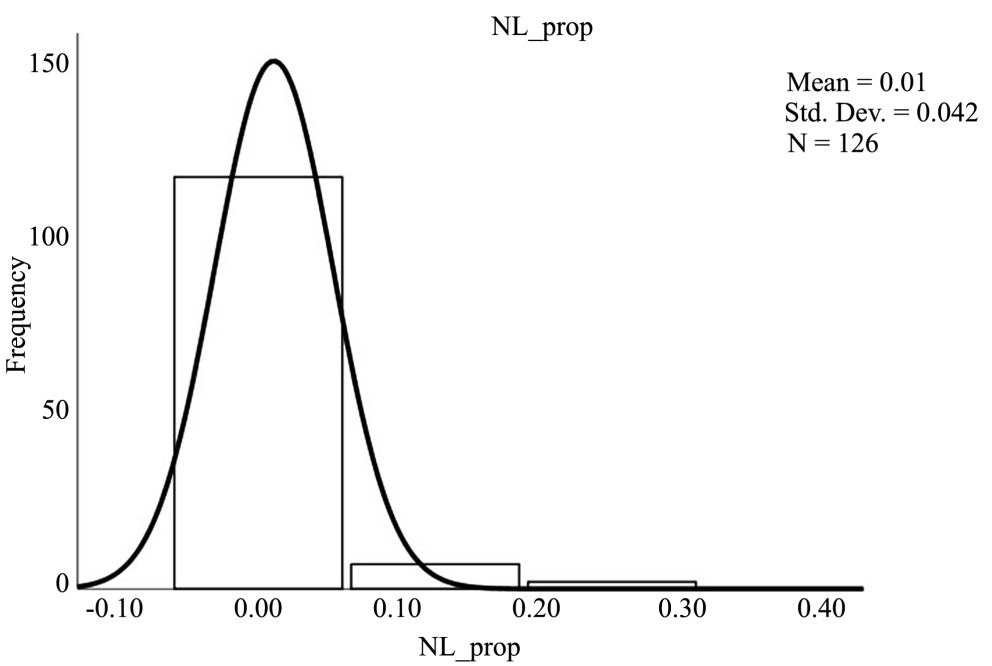

Figure A3.8. Histograms for covariates and dependent variables.

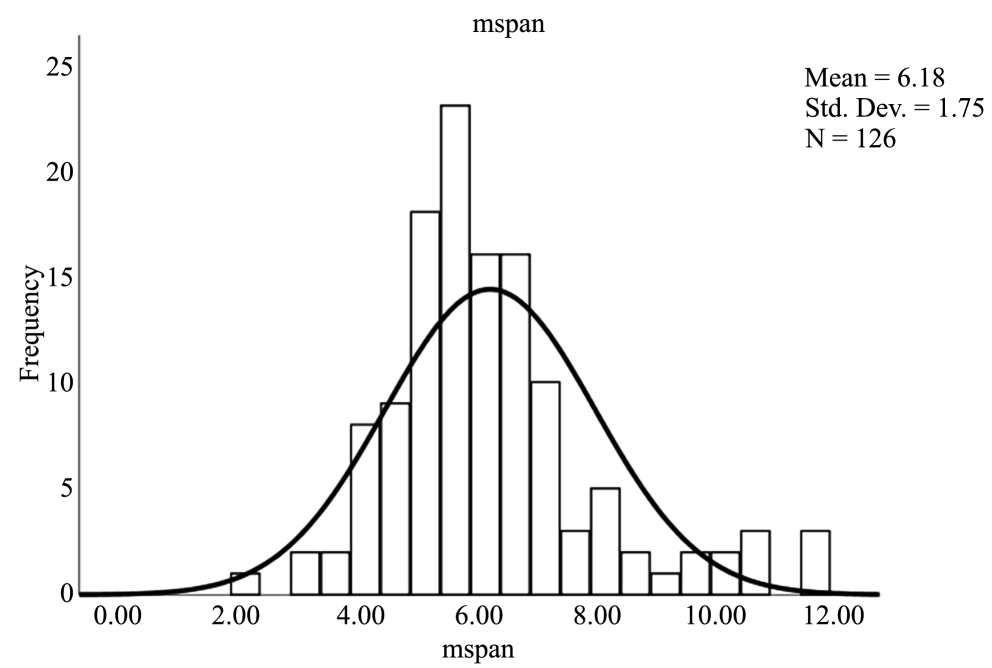

Figure A3.9. Histograms for covariates and dependent variables. 
4) Box and Whisker Plots for Covariates and Dependent Variables assessing Univariate Outliers

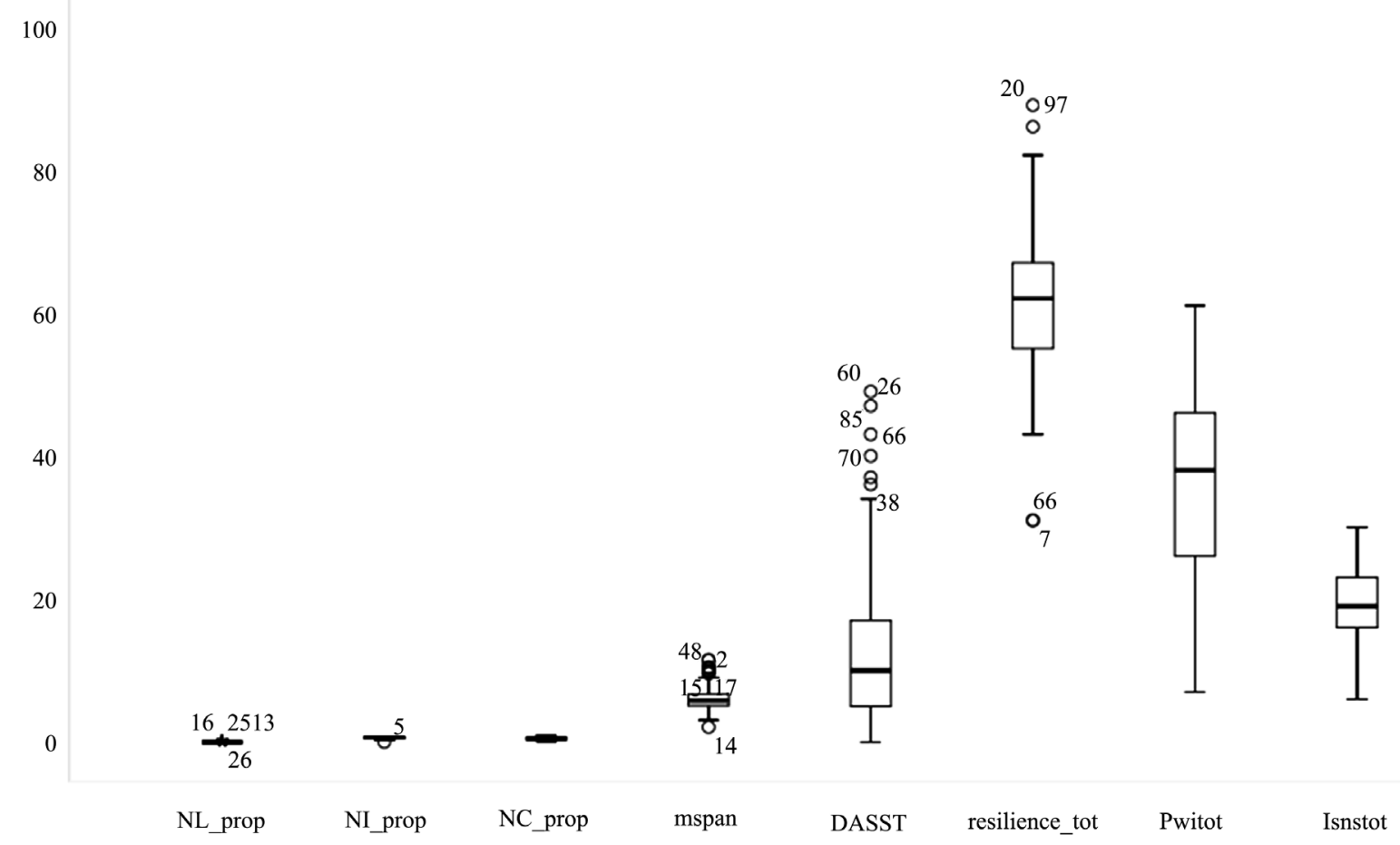

Figure A4. Box and Whisker Plots for Covariates and Dependent Variables assessing Univariate Outliers.

\section{MANCOVA Analysis Output}

Table A3. MANCOVA Analysis Output: Box's test of equality of covariance matrices.

\begin{tabular}{cc}
\hline Box's test of equality of covariance matrices & \\
\hline Box's M & 41.640 \\
F & 1.186 \\
df1 & 30 \\
df2 & 3994.987 \\
Sig. & 0.224 \\
\hline
\end{tabular}

Table A4. MANCOVA Analysis Output: Levene's test of equality of error variances.

\begin{tabular}{ccccc}
\hline Levene's test of equality of error variances $^{2}$ & & & \\
\hline & $\mathrm{F}$ & $\mathrm{df1}$ & $\mathrm{df2}$ & Sig. \\
\hline NL_prop & 3.872 & 15 & 98 & 0.000 \\
NI_prop & 1.488 & 15 & 98 & 0.125 \\
NC_prop & 1.701 & 15 & 98 & 0.063 \\
mspan & 1.380 & 15 & 98 & 0.172 \\
\hline
\end{tabular}


Table A5. Multivariate statistics SPSS output displaying main effects and interactions for the $3 \times 3 \times 2$ MANCOVA examining age, gender, and marital status across age-associated cognitive decline controlling for social networks, depression, personal WellBeing, and resilience.

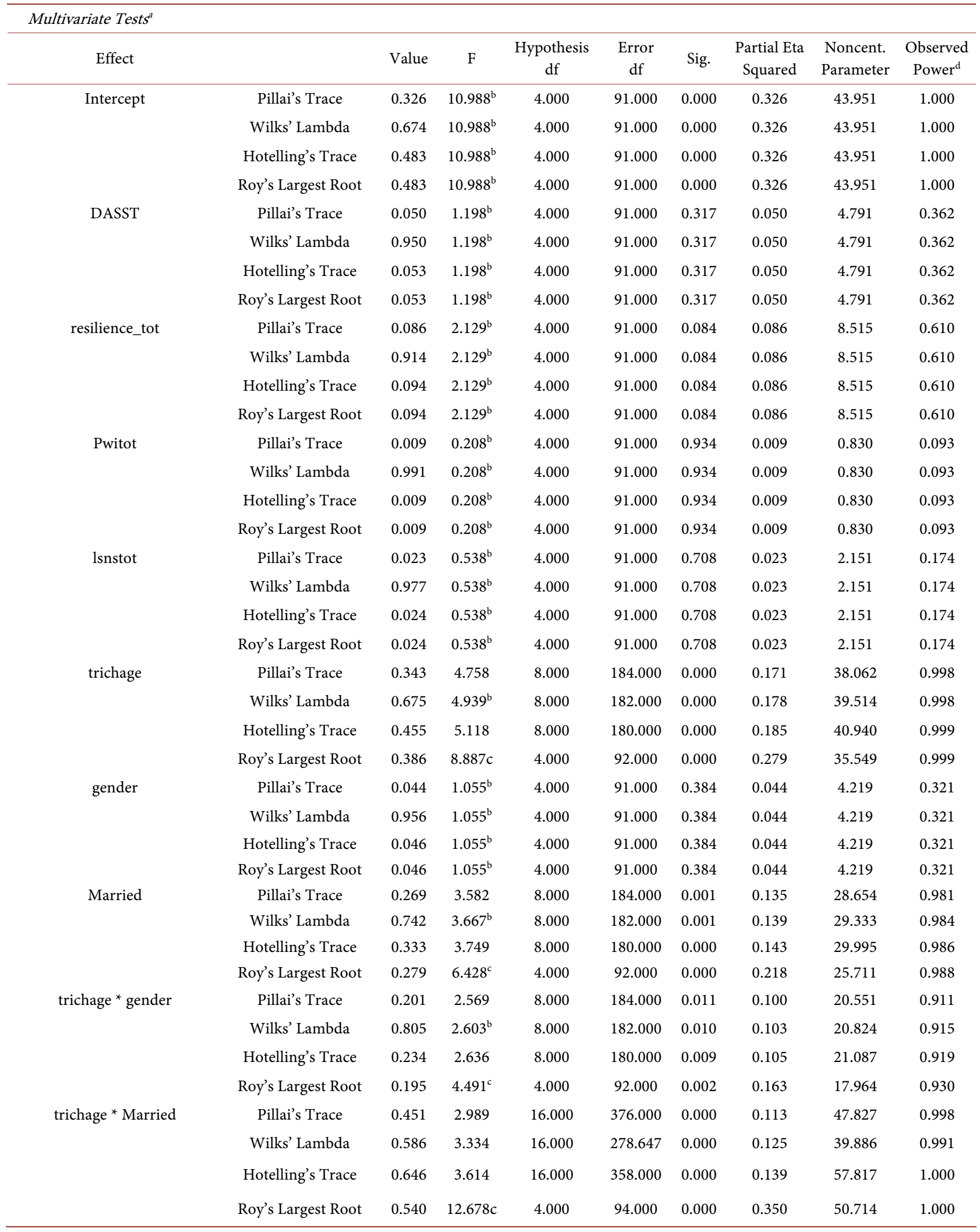




\section{Continued}

\begin{tabular}{ccccccccccc}
\hline gender * Married & Pillai's Trace & 0.104 & 1.267 & 8.000 & 184.000 & 0.263 & 0.052 & 10.133 & 0.573 \\
& Wilks' Lambda & 0.897 & $1.273^{\mathrm{b}}$ & 8.000 & 182.000 & 0.260 & 0.053 & 10.184 & 0.575 \\
& Hotelling's Trace & 0.114 & 1.279 & 8.000 & 180.000 & 0.257 & 0.054 & 10.231 & 0.577 \\
& Roy's Largest Root & 0.100 & $2.302 \mathrm{c}$ & 4.000 & 92.000 & 0.064 & 0.091 & 9.210 & 0.649 \\
& Pillai's Trace & 0.143 & 1.770 & 8.000 & 184.000 & 0.085 & 0.071 & 14.160 & 0.750 \\
trichage* gender * Married & Wilks' Lambda & 0.862 & $1.760^{\mathrm{b}}$ & 8.000 & 182.000 & 0.088 & 0.072 & 14.082 & 0.747 \\
& Hotelling's Trace & 0.156 & 1.750 & 8.000 & 180.000 & 0.090 & 0.072 & 14.001 & 0.744 \\
& Roy's Largest Root & 0.108 & $2.475^{\mathrm{c}}$ & 4.000 & 92.000 & 0.050 & 0.097 & 9.901 & 0.686 \\
\hline
\end{tabular}

Note. $N=126$. Pillai's Trace $F$ statistic was reported.

\section{MANOVA analysis output}

Table A6. MANOVA Analysis Output: Box's test of equality of covariance matrices.

\begin{tabular}{cc}
\hline Box's test of equality of covariance matrices $^{2}$ & \\
\hline Box's M & 41.912 \\
F & 1.194 \\
df1 & 30 \\
df2 & 3966.255 \\
Sig. & 0.215 \\
\hline
\end{tabular}

Table A7. MANOVA Analysis Output: Levene's test of equality of error variances.

\begin{tabular}{|c|c|c|c|c|c|}
\hline \multicolumn{6}{|c|}{ Levene's test of equality of error variances ${ }^{2}$} \\
\hline & & $\begin{array}{l}\text { Levene } \\
\text { Statistic }\end{array}$ & df1 & df2 & Sig. \\
\hline \multirow[t]{4}{*}{ NL_prop } & Based on Mean & 9.300 & 12 & 103 & 0.000 \\
\hline & Based on Median & 3.490 & 12 & 103 & 0.000 \\
\hline & Based on Median and with adjusted df & 3.490 & 12 & 16.899 & 0.010 \\
\hline & Based on trimmed mean & 7.382 & 12 & 103 & 0.000 \\
\hline \multirow[t]{4}{*}{ NI_prop } & Based on Mean & 1.444 & 12 & 103 & 0.158 \\
\hline & Based on Median & 0.757 & 12 & 103 & 0.693 \\
\hline & Based on Median and with adjusted df & 0.757 & 12 & 82.469 & 0.692 \\
\hline & Based on trimmed mean & 1.394 & 12 & 103 & 0.181 \\
\hline \multirow[t]{4}{*}{ NC_prop } & Based on Mean & 1.849 & 12 & 103 & 0.050 \\
\hline & Based on Median & 1.447 & 12 & 103 & 0.157 \\
\hline & Based on Median and with adjusted df & 1.447 & 12 & 82.703 & 0.162 \\
\hline & Based on trimmed mean & 1.812 & 12 & 103 & 0.056 \\
\hline \multirow[t]{4}{*}{ mspan } & Based on Mean & 1.854 & 12 & 103 & 0.049 \\
\hline & Based on Median & 1.035 & 12 & 103 & 0.424 \\
\hline & Based on Median and with adjusted df & 1.035 & 12 & 57.635 & 0.431 \\
\hline & Based on trimmed mean & 1.772 & 12 & 103 & 0.063 \\
\hline
\end{tabular}


Table A8. Multivariate statistics SPSS output displaying main effects and interactions for the $3 \times 3 \times 2$ MANOVA examining age, gender, and marital status across age-associated cognitive decline.

\begin{tabular}{|c|c|c|c|c|c|c|c|c|c|}
\hline Multivariate Tests & & & & & & & & & \\
\hline Effect & & Value & $\mathrm{F}$ & $\begin{array}{l}\text { Hypothesis } \\
\text { df }\end{array}$ & $\begin{array}{l}\text { Error } \\
\text { df }\end{array}$ & Sig. & $\begin{array}{c}\text { Partial Eta } \\
\text { Squared }\end{array}$ & $\begin{array}{l}\text { Noncent. } \\
\text { Parameter }\end{array}$ & $\begin{array}{c}\text { Observed } \\
\text { Powerd }\end{array}$ \\
\hline \multirow[t]{4}{*}{ Intercept } & Pillai's Trace & 0.896 & $215.914 b$ & 4.000 & 100.000 & 0.000 & 0.896 & 863.656 & 1.000 \\
\hline & Wilks' Lambda & 0.104 & $215.914 b$ & 4.000 & 100.000 & 0.000 & 0.896 & 863.656 & 1.000 \\
\hline & Hotelling’s Trace & 8.637 & $215.914 b$ & 4.000 & 100.000 & 0.000 & 0.896 & 863.656 & 1.000 \\
\hline & Roy's Largest Root & 8.637 & $215.914 b$ & 4.000 & 100.000 & 0.000 & 0.896 & 863.656 & 1.000 \\
\hline \multirow[t]{4}{*}{ trichage } & Pillai's Trace & 0.223 & 3.172 & 8.000 & 202.000 & 0.002 & 0.112 & 25.372 & 0.964 \\
\hline & Wilks' Lambda & 0.786 & $3.196 b$ & 8.000 & 200.000 & 0.002 & 0.113 & 25.565 & 0.966 \\
\hline & Hotelling's Trace & 0.260 & 3.219 & 8.000 & 198.000 & 0.002 & 0.115 & 25.750 & 0.967 \\
\hline & Roy's Largest Root & 0.201 & $5.073 c$ & 4.000 & 101.000 & 0.001 & 0.167 & 20.293 & 0.958 \\
\hline \multirow[t]{4}{*}{ gender } & Pillai's Trace & 0.025 & $0.636 \mathrm{~b}$ & 4.000 & 100.000 & 0.638 & 0.025 & 2.545 & 0.202 \\
\hline & Wilks' Lambda & 0.975 & $0.636 \mathrm{~b}$ & 4.000 & 100.000 & 0.638 & 0.025 & 2.545 & 0.202 \\
\hline & Hotelling's Trace & 0.025 & $0.636 \mathrm{~b}$ & 4.000 & 100.000 & 0.638 & 0.025 & 2.545 & 0.202 \\
\hline & Roy's Largest Root & 0.025 & $0.636 \mathrm{~b}$ & 4.000 & 100.000 & 0.638 & 0.025 & 2.545 & 0.202 \\
\hline \multirow[t]{4}{*}{ Married } & Pillai's Trace & 0.171 & 2.364 & 8.000 & 202.000 & 0.019 & 0.086 & 18.911 & 0.883 \\
\hline & Wilks' Lambda & 0.830 & $2.437 \mathrm{~b}$ & 8.000 & 200.000 & 0.016 & 0.089 & 19.498 & 0.894 \\
\hline & Hotelling’s Trace & 0.203 & 2.509 & 8.000 & 198.000 & 0.013 & 0.092 & 20.071 & 0.904 \\
\hline & Roy's Largest Root & 0.194 & $4.892 \mathrm{c}$ & 4.000 & 101.000 & 0.001 & 0.162 & 19.569 & 0.951 \\
\hline \multirow[t]{4}{*}{ trichage ${ }^{*}$ gender } & Pillai's Trace & 0.137 & 1.856 & 8.000 & 202.000 & 0.069 & 0.068 & 14.849 & 0.776 \\
\hline & Wilks' Lambda & 0.865 & $1.874 \mathrm{~b}$ & 8.000 & 200.000 & 0.066 & 0.070 & 14.994 & 0.780 \\
\hline & Hotelling's Trace & 0.153 & 1.892 & 8.000 & 198.000 & 0.063 & 0.071 & 15.134 & 0.785 \\
\hline & Roy's Largest Root & 0.133 & $3.346 \mathrm{c}$ & 4.000 & 101.000 & 0.013 & 0.117 & 13.384 & 0.830 \\
\hline \multirow[t]{4}{*}{ trichage ${ }^{\star}$ Married } & Pillai's Trace & 0.272 & 1.882 & 16.000 & 412.000 & 0.020 & 0.068 & 30.114 & 0.956 \\
\hline & Wilks' Lambda & 0.742 & 1.966 & 16.000 & 306.143 & 0.015 & 0.072 & 23.746 & 0.877 \\
\hline & Hotelling's Trace & 0.329 & 2.028 & 16.000 & 394.000 & 0.011 & 0.076 & 32.447 & 0.970 \\
\hline & Roy's Largest Root & 0.261 & $6.729 c$ & 4.000 & 103.000 & 0.000 & 0.207 & 26.918 & 0.991 \\
\hline \multirow[t]{4}{*}{ gender ${ }^{*}$ Married } & Pillai's Trace & 0.035 & 0.450 & 8.000 & 202.000 & 0.889 & 0.018 & 3.604 & 0.208 \\
\hline & Wilks' Lambda & 0.965 & $0.446 \mathrm{~b}$ & 8.000 & 200.000 & 0.892 & 0.018 & 3.570 & 0.206 \\
\hline & Hotelling’s Trace & 0.036 & 0.442 & 8.000 & 198.000 & 0.895 & 0.018 & 3.536 & 0.204 \\
\hline & Roy's Largest Root & 0.022 & $0.564 \mathrm{c}$ & 4.000 & 101.000 & 0.689 & 0.022 & 2.258 & 0.182 \\
\hline \multirow[t]{4}{*}{ trichage ${ }^{\star}$ gender ${ }^{\star}$ Married } & Pillai's Trace & 0.086 & 1.133 & 8.000 & 202.000 & 0.342 & 0.043 & 9.065 & 0.518 \\
\hline & Wilks' Lambda & 0.915 & $1.135 b$ & 8.000 & 200.000 & 0.341 & 0.043 & 9.081 & 0.519 \\
\hline & Hotelling's Trace & 0.092 & 1.137 & 8.000 & 198.000 & 0.340 & 0.044 & 9.094 & 0.520 \\
\hline & Roy's Largest Root & 0.079 & $1.998 \mathrm{c}$ & 4.000 & 101.000 & 0.101 & 0.073 & 7.992 & 0.581 \\
\hline
\end{tabular}

Note. $\mathrm{N}=126$. Pillai's Trace F statistic was reported. 
Table A9. Multivariate statistics SPSS output displaying between-subjects effects and interactions for the $3 \times 3 \times 2$ MANOVA examining age, gender, and marital status across age-associated cognitive decline.

\begin{tabular}{|c|c|c|c|c|c|c|c|c|c|}
\hline \multicolumn{10}{|c|}{ Tests of Between-Subjects Effects. } \\
\hline Source & $\begin{array}{c}\text { Dependent } \\
\text { Variable }\end{array}$ & $\begin{array}{l}\text { Type III } \\
\text { Sum of } \\
\text { Squares }\end{array}$ & df & $\begin{array}{l}\text { Mean } \\
\text { Square }\end{array}$ & $\mathrm{F}$ & Sig. & $\begin{array}{c}\text { Partial Eta } \\
\text { Squared }\end{array}$ & $\begin{array}{l}\text { Noncent. } \\
\text { Parameter }\end{array}$ & $\begin{array}{c}\text { Observed } \\
\text { Powere }\end{array}$ \\
\hline \multirow[t]{4}{*}{ Corrected Model } & NL_prop & $0.061 \mathrm{a}$ & 15 & 0.004 & 2.675 & 0.002 & 0.280 & 40.126 & 0.988 \\
\hline & NI_prop & $0.743 b$ & 15 & 0.050 & 1.338 & 0.193 & 0.163 & 20.072 & 0.774 \\
\hline & NC_prop & $0.786 \mathrm{c}$ & 15 & 0.052 & 1.685 & 0.065 & 0.197 & 25.274 & 0.882 \\
\hline & mspan & $30.293 \mathrm{~d}$ & 15 & 2.020 & 0.630 & 0.844 & 0.084 & 9.451 & 0.383 \\
\hline \multirow[t]{4}{*}{ Intercept } & NL_prop & 0.016 & 1 & 0.016 & 10.188 & 0.002 & 0.090 & 10.188 & 0.885 \\
\hline & NI_prop & 12.692 & 1 & 12.692 & 343.068 & 0.000 & 0.769 & 343.068 & 1.000 \\
\hline & NC_prop & 6.519 & 1 & 6.519 & 209.759 & 0.000 & 0.671 & 209.759 & 1.000 \\
\hline & mspan & 1207.098 & 1 & 1207.098 & 376.619 & 0.000 & 0.785 & 376.619 & 1.000 \\
\hline \multirow{4}{*}{ trichage } & NL_prop & 0.026 & 2 & 0.013 & 8.592 & 0.000 & 0.143 & 17.185 & 0.964 \\
\hline & NI_prop & 0.174 & 2 & 0.087 & 2.355 & 0.100 & 0.044 & 4.709 & 0.467 \\
\hline & NC_prop & 0.151 & 2 & 0.075 & 2.427 & 0.093 & 0.045 & 4.854 & 0.479 \\
\hline & mspan & 0.498 & 2 & 0.249 & 0.078 & 0.925 & 0.002 & 0.155 & 0.062 \\
\hline \multirow[t]{4}{*}{ gender } & NL_prop & 0.000 & 1 & 0.000 & 0.150 & 0.699 & 0.001 & 0.150 & 0.067 \\
\hline & NI_prop & 0.058 & 1 & 0.058 & 1.573 & 0.213 & 0.015 & 1.573 & 0.237 \\
\hline & NC_prop & 0.003 & 1 & 0.003 & 0.106 & 0.746 & 0.001 & 0.106 & 0.062 \\
\hline & mspan & 4.059 & 1 & 4.059 & 1.266 & 0.263 & 0.012 & 1.266 & 0.200 \\
\hline \multirow[t]{4}{*}{ Married } & NL_prop & 0.014 & 2 & 0.007 & 4.560 & 0.013 & 0.081 & 9.120 & 0.764 \\
\hline & NI_prop & 0.236 & 2 & 0.118 & 3.186 & 0.045 & 0.058 & 6.371 & 0.598 \\
\hline & NC_prop & 0.131 & 2 & 0.065 & 2.101 & 0.127 & 0.039 & 4.203 & 0.423 \\
\hline & mspan & 2.095 & 2 & 1.047 & 0.327 & 0.722 & 0.006 & 0.654 & 0.101 \\
\hline \multirow[t]{4}{*}{ trichage ${ }^{\star}$ gender } & NL_prop & 0.006 & 2 & 0.003 & 1.947 & 0.148 & 0.036 & 3.895 & 0.395 \\
\hline & NI_prop & 0.130 & 2 & 0.065 & 1.761 & 0.177 & 0.033 & 3.523 & 0.362 \\
\hline & NC_prop & 0.082 & 2 & 0.041 & 1.317 & 0.272 & 0.025 & 2.635 & 0.279 \\
\hline & mspan & 13.544 & 2 & 6.772 & 2.113 & 0.126 & 0.039 & 4.226 & 0.425 \\
\hline \multirow[t]{4}{*}{ trichage ${ }^{\star}$ Married } & NL_prop & 0.023 & 4 & 0.006 & 3.783 & 0.007 & 0.128 & 15.130 & 0.878 \\
\hline & NI_prop & 0.427 & 4 & 0.107 & 2.888 & 0.026 & 0.101 & 11.552 & 0.764 \\
\hline & NC_prop & 0.207 & 4 & 0.052 & 1.666 & 0.164 & 0.061 & 6.663 & 0.496 \\
\hline & mspan & 5.625 & 4 & 1.406 & 0.439 & 0.780 & 0.017 & 1.755 & 0.149 \\
\hline \multirow[t]{4}{*}{ gender ${ }^{\star}$ Married } & NL_prop & 0.000 & 2 & 0.000 & 0.104 & 0.901 & 0.002 & 0.209 & 0.066 \\
\hline & NI_prop & 0.072 & 2 & 0.036 & 0.979 & 0.379 & 0.019 & 1.958 & 0.216 \\
\hline & NC_prop & 0.024 & 2 & 0.012 & 0.391 & 0.677 & 0.008 & 0.782 & 0.112 \\
\hline & mspan & 2.527 & 2 & 1.264 & 0.394 & 0.675 & 0.008 & 0.789 & 0.112 \\
\hline
\end{tabular}




\section{Continued}

\begin{tabular}{|c|c|c|c|c|c|c|c|c|c|}
\hline \multirow[t]{4}{*}{ trichage ${ }^{\star}$ gender ${ }^{\star}$ Married } & NL_prop & 0.005 & 2 & 0.002 & 10.563 & 0.214 & 0.029 & 3.126 & 0.325 \\
\hline & NI_prop & 0.011 & 2 & 0.005 & 0.144 & 0.866 & 0.003 & 0.287 & 0.072 \\
\hline & NC_prop & 0.098 & 2 & 0.049 & 1.580 & 0.211 & 0.030 & 3.160 & 0.328 \\
\hline & mspan & 7.124 & 2 & 3.562 & 1.111 & 0.333 & 0.021 & 2.223 & 0.241 \\
\hline \multirow[t]{4}{*}{ Error } & NL_prop & 0.157 & 103 & 0.002 & & & & & \\
\hline & NI_prop & 3.810 & 103 & 0.037 & & & & & \\
\hline & NC_prop & 3.201 & 103 & 0.031 & & & & & \\
\hline & mspan & 330.125 & 103 & 3.205 & & & & & \\
\hline \multirow[t]{4}{*}{ Total } & NL_prop & 0.234 & 119 & & & & & & \\
\hline & NI_prop & 56.172 & 119 & & & & & & \\
\hline & NC_prop & 30.813 & 119 & & & & & & \\
\hline & mspan & 4903.830 & 119 & & & & & & \\
\hline \multirow[t]{4}{*}{ Corrected Total } & NL_prop & 0.218 & 118 & & & & & & \\
\hline & NI_prop & 4.553 & 118 & & & & & & \\
\hline & NC_prop & 3.987 & 118 & & & & & & \\
\hline & mspan & 360.417 & 118 & & & & & & \\
\hline
\end{tabular}

One-Way ANOVA analysis output for the interaction between marital status and age on new location.

One-way ANOVA analysis output for the interaction between marital status and age on new location

Table A10. One-way ANOVA analysis output for the interaction between marital status and age on New Location.

\begin{tabular}{lccc}
\hline Married = Defacto & & \\
\hline Between-Subjects factors ${ }^{\text {. }}$ & & & \\
\hline & & Value Label & $\mathrm{N}$ \\
\hline trichotomous age & 0.00 & $<27$ & 13 \\
& 1.00 & $27-62$ & 4 \\
& 2.00 & $62+$ & \\
\hline
\end{tabular}

a. Married $=$ Defacto.

Table A11. One-way ANOVA analysis output for the interaction between marital status and age on New Location.

\begin{tabular}{cccc}
\hline \multicolumn{2}{l}{${\text { Descriptive } \text { statistics }^{{ }^{2}}}^{2}$} & & \\
\hline \multicolumn{2}{l}{ Dependent Variable: NL_prop } & & \\
\hline trichotomous age & Mean & Std. Deviation & $\mathrm{N}$ \\
\hline$<27$ & 0.0288 & 0.07489 & 13 \\
$27-62$ & 0.0313 & 0.06250 & 4 \\
$62+$ & 0.0000 & & 1 \\
Total & 0.0278 & 0.06854 & 18 \\
\hline
\end{tabular}

a. Married $=$ Defacto. 
Table A12. One-way ANOVA analysis output for the interaction between marital status and age on New Location.

\begin{tabular}{cccccccccc}
\hline \multicolumn{2}{l}{ Tests of Between-Subjects Effects $^{a}$} \\
\hline Dependent Variable: NL_prop \\
Source & $\begin{array}{c}\text { Type III Sum } \\
\text { of Squares }\end{array}$ & df & $\begin{array}{c}\text { Mean } \\
\text { Square }\end{array}$ & F & Sig. & $\begin{array}{c}\text { Partial Eta } \\
\text { Squared }\end{array}$ & $\begin{array}{c}\text { Noncent. } \\
\text { Parameter }\end{array}$ & $\begin{array}{c}\text { Observed } \\
\text { Power }\end{array}$ \\
\hline Corrected Model & $0.001^{\mathrm{b}}$ & 2 & 0.000 & 0.079 & 0.924 & 0.010 & 0.158 & 0.060 \\
Intercept & 0.003 & 1 & 0.003 & 0.517 & 0.483 & 0.033 & 0.517 & 0.103 \\
trichage & 0.001 & 2 & 0.000 & 0.079 & 0.924 & 0.010 & 0.158 & 0.060 \\
Error & 0.079 & 15 & 0.005 & & & & & \\
Total & 0.094 & 18 & & & & & & \\
Corrected Total & 0.080 & 17 & & & & & & \\
\hline
\end{tabular}

${ }^{\mathrm{a}}$ Married $=$ Defacto; ${ }^{\mathrm{b} R}$ Squared $=0.010$ (Adjusted R Squared $=-0.121$ ); ${ }^{\mathrm{c} C o m p u t e d ~ u s i n g ~ a l p h a ~}=0.05$.

Table A13. One-way ANOVA analysis output for the interaction between marital status and age on New Location.

\begin{tabular}{lccc}
\hline Married = Married & & \\
\hline Between-Subjects factors $^{a}$ & & Value Label & $\mathrm{N}$ \\
\hline & & $<27$ & 3 \\
\hline trichotomous age & 0.00 & $27-62$ & 35 \\
& 1.00 & $62+$ & 26 \\
\hline
\end{tabular}

a. Married = Married.

Table A14. One-way ANOVA analysis output for the interaction between marital status and age on New Location.

\begin{tabular}{cccc}
\hline Descriptive Statistics $^{2}$ & & \\
\hline Dependent variable: NL_prop & & & \\
\hline trichotomous age & Mean & Std. Deviation & $\mathrm{N}$ \\
\hline$<27$ & 0.1250 & 0.12500 & 3 \\
$27-62$ & 0.0036 & 0.02113 & 35 \\
$62+$ & 0.0000 & 0.00000 & 26 \\
Total & 0.0078 & 0.03776 & 64 \\
\hline
\end{tabular}

a. Married = Married.

Table A15. One-way ANOVA analysis output for the interaction between marital status and age on New Location.

\begin{tabular}{|c|c|c|c|c|c|c|c|c|}
\hline \multicolumn{9}{|c|}{ Tests of between-subjects effects ${ }^{a}$} \\
\hline \multicolumn{9}{|c|}{ Dependent variable: NL_prop } \\
\hline Source & $\begin{array}{l}\text { Type III Sum } \\
\text { of Squares }\end{array}$ & df & $\begin{array}{l}\text { Mean } \\
\text { Square }\end{array}$ & $\mathrm{F}$ & Sig. & $\begin{array}{c}\text { Partial Eta } \\
\text { Squared }\end{array}$ & $\begin{array}{l}\text { Noncent. } \\
\text { Parameter }\end{array}$ & $\begin{array}{c}\text { Observed } \\
\text { Power }^{c}\end{array}$ \\
\hline Corrected Model & $0.043^{\mathrm{b}}$ & 2 & 0.022 & 28.520 & 0.000 & 0.483 & 57.041 & 1.000 \\
\hline Intercept & 0.041 & 1 & 0.041 & 54.247 & 0.000 & 0.471 & 54.247 & 1.000 \\
\hline
\end{tabular}


Continued

\begin{tabular}{ccccccccc}
\hline trichage & 0.043 & 2 & 0.022 & 28.520 & 0.000 & 0.483 & 57.041 & 1.000 \\
Error & 0.046 & 61 & 0.001 & & & & & \\
Total & 0.094 & 64 & & & & & & \\
Corrected Total & 0.090 & 63 & & & & & & \\
\hline
\end{tabular}

${ }^{\mathrm{a}}$ Married $=$ Married; ${ }^{\mathrm{b}} \mathrm{R}$ Squared $=0.483$ (Adjusted R Squared $=0.466$ ); ${ }^{\mathrm{c} C o m p u t e d}$ using alpha $=0.05$.

Table A16. One-way ANOVA analysis output for the interaction between marital status and age on New Location.

\begin{tabular}{lccc}
\hline Married = Single & & \\
\hline Between-subjects factors $^{a}$ & & & \\
\hline & & Value Label & $\mathrm{N}$ \\
\hline trichotomous age & 0.00 & $<27$ & 32 \\
& 1.00 & $27-62$ & 2 \\
& 2.00 & $62+$ & 4 \\
\hline
\end{tabular}

${ }^{a}$ Married $=$ Single.

Table A17. One-way ANOVA analysis output for the interaction between marital status and age on New Location.

\begin{tabular}{cccc}
\hline \multicolumn{2}{l}{${\text { Descriptive } \text { statistics }^{2}}^{2}$} & & \\
\hline \multicolumn{2}{l}{ Dependent Variable: NL_prop } & & \\
\hline trichotomous age & Mean & Std. Deviation & $\mathrm{N}$ \\
\hline$<27$ & 0.0117 & 0.03702 & 32 \\
$27-62$ & 0.0000 & 0.00000 & 2 \\
$62+$ & 0.0000 & 0.00000 & 4 \\
Total & 0.0099 & 0.03416 & 38 \\
\hline
\end{tabular}

${ }^{\mathrm{a}}$ Married $=$ Single.

Table A18. One-way ANOVA analysis output for the interaction between marital status and age on New Location.

\begin{tabular}{ccccccccc}
\hline \multicolumn{2}{c}{ Tests of between-subjects effects $^{a}$} & & & & & & \\
\hline Dependent variable: NL_prop & & & & & & & \\
\hline Source & $\begin{array}{c}\text { Type III Sum } \\
\text { of Squares }\end{array}$ & df & $\begin{array}{c}\text { Mean } \\
\text { Square }\end{array}$ & F & Sig. & $\begin{array}{c}\text { Partial Eta } \\
\text { Squared }\end{array}$ & $\begin{array}{c}\text { Noncent. } \\
\text { Parameter }\end{array}$ & $\begin{array}{c}\text { Observed } \\
\text { Power }^{\mathrm{c}}\end{array}$ \\
\hline Corrected Model & $0.001^{\mathrm{b}}$ & 2 & 0.000 & 0.286 & 0.753 & 0.016 & 0.572 & 0.092 \\
Intercept & 0.000 & 1 & 0.000 & 0.145 & 0.706 & 0.004 & 0.145 & 0.066 \\
trichage & 0.001 & 2 & 0.000 & 0.286 & 0.753 & 0.016 & 0.572 & 0.092 \\
Error & 0.042 & 35 & 0.001 & & & & & \\
Total & 0.047 & 38 & & & & & & \\
Corrected Total & 0.043 & 37 & & & & & & \\
\hline
\end{tabular}

${ }^{\mathrm{a}}$ Married $=$ Single; ${ }^{\mathrm{b}} \mathrm{R}$ Squared $=0.016$ (Adjusted R Squared $=-0.040$ ); ${ }^{\mathrm{c} C o m p u t e d}$ using alpha $=0.05$.

One-Way ANOVA Analysis Output for the Interaction Between Marital Status and Age on New Image 
Table A19. One-Way ANOVA Analysis Output for the Interaction Between Marital Status and Age on New Image.

\begin{tabular}{cccc}
\hline Married = Defacto & & \\
\hline Between-subjects factors $^{a}$ & & & \\
\hline & & Value Label & $\mathrm{N}$ \\
\hline trichotomous age & 0.00 & $<27$ & 13 \\
& 1.00 & $27-62$ & 4 \\
& 2.00 & $62+$ & 1 \\
\hline
\end{tabular}

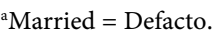

Table A20. One-Way ANOVA Analysis Output for the Interaction Between Marital Status and Age on New Image.

\begin{tabular}{cccc}
\hline Descriptive statistics $^{2}$ & & & \\
\hline Dependent variable: NI_prop & & & \\
\hline trichotomous age & Mean & Std. Deviation & $\mathrm{N}$ \\
\hline$<27$ & 0.7019 & 0.09599 & 13 \\
$27-62$ & 0.5938 & 0.21348 & 4 \\
$62+$ & 0.5000 & & 1 \\
Total & 0.6667 & 0.13558 & 18 \\
\hline
\end{tabular}

a. Married $=$ Defacto

Table A21. One-Way ANOVA Analysis Output for the Interaction Between Marital Status and Age on New Image.

\begin{tabular}{|c|c|c|c|c|c|c|c|c|}
\hline \multicolumn{9}{|c|}{ Tests of between-subjects effects } \\
\hline \multicolumn{9}{|c|}{ Dependent variable: NI_prop } \\
\hline Source & $\begin{array}{c}\text { Type III Sum } \\
\text { of Squares }\end{array}$ & $\mathrm{df}$ & $\begin{array}{l}\text { Mean } \\
\text { Square }\end{array}$ & $\mathrm{F}$ & Sig. & $\begin{array}{c}\text { Partial Eta } \\
\text { Squared }\end{array}$ & $\begin{array}{l}\text { Noncent. } \\
\text { Parameter }\end{array}$ & $\begin{array}{c}\text { Observed } \\
\text { Power }^{c}\end{array}$ \\
\hline Corrected Model & $0.065^{\mathrm{b}}$ & 2 & 0.033 & 1.978 & 0.173 & 0.209 & 3.955 & 0.344 \\
\hline Intercept & 2.430 & 1 & 2.430 & 147.395 & 0.000 & 0.908 & 147.395 & 1.000 \\
\hline trichage & 0.065 & 2 & 0.033 & 1.978 & 0.173 & 0.209 & 3.955 & 0.344 \\
\hline Error & 0.247 & 15 & 0.016 & & & & & \\
\hline Total & 8.313 & 18 & & & & & & \\
\hline Corrected Total & 0.313 & 17 & & & & & & \\
\hline
\end{tabular}

${ }^{\mathrm{a}}$ Married $=$ Defacto; ${ }^{\mathrm{b}} \mathrm{R}$ Squared $=0.209$ (Adjusted $\mathrm{R}$ Squared $\left.=0.103\right) ;{ }^{\mathrm{c} C o m p u t e d}$ using alpha $=0.05$.

Table A22. One-Way ANOVA Analysis Output for the Interaction Between Marital Status and Age on New Image.

\begin{tabular}{lccc}
\hline Married = Married & & \\
\hline Between-subjects factors & & \\
\hline & & & \\
\hline trichotomous age & 0.00 & Value Label & $\mathrm{N}$ \\
& 1.00 & $<27$ & 35 \\
& 2.00 & $27-62$ & 26 \\
\hline
\end{tabular}

a. Married = Married. 
Table A23. One-Way ANOVA Analysis Output for the Interaction Between Marital Status and Age on New Image.

\begin{tabular}{cccc}
\hline \multicolumn{4}{c}{ Descriptive statistics $^{\mathrm{a}}$} \\
\hline \multicolumn{4}{c}{ Dependent variable: NI_prop } \\
\hline trichotomous age & Mean & Std. Deviation & $\mathrm{N}$ \\
\hline$<27$ & 0.2917 & 0.14434 & 3 \\
$27-62$ & 0.6714 & 0.23500 & 35 \\
$62+$ & 0.6587 & 0.19544 & 26 \\
Total & 0.6484 & 0.22808 & 64 \\
\hline
\end{tabular}

a. Married = Married.

Table A24. One-Way ANOVA Analysis Output for the Interaction Between Marital Status and Age on New Image.

\begin{tabular}{cccccccccc}
\hline \multicolumn{2}{c}{ Tests of between-subjects effects $^{\mathrm{a}}$} \\
\hline \multicolumn{2}{c}{ Dependent variable: NI_prop } \\
\hline Source & $\begin{array}{c}\text { Type III Sum } \\
\text { of Squares }\end{array}$ & df & $\begin{array}{c}\text { Mean } \\
\text { Square }\end{array}$ & F & Sig. & $\begin{array}{c}\text { Partial Eta } \\
\text { Squared }\end{array}$ & $\begin{array}{c}\text { Noncent. } \\
\text { Parameter }\end{array}$ & $\begin{array}{c}\text { Observed } \\
\text { Power }\end{array}$ \\
\hline Corrected Model & $0.403^{\mathrm{b}}$ & 2 & 0.202 & 4.277 & 0.018 & 0.123 & 8.554 & 0.726 \\
Intercept & 6.569 & 1 & 6.569 & 139.416 & 0.000 & 0.696 & 139.416 & 1.000 \\
trichage & 0.403 & 2 & 0.202 & 4.277 & 0.018 & 0.123 & 8.554 & 0.726 \\
Error & 2.874 & 61 & 0.047 & & & & & \\
Total & 30.188 & 64 & & & & & & \\
Corrected Total & 3.277 & 63 & & & & & & \\
\hline
\end{tabular}

${ }^{\mathrm{a}}$ Married $=$ Married; ${ }^{\mathrm{b} R}$ Squared $=0.123$ (Adjusted R Squared $=.094$ ); ${ }^{\mathrm{c} C o m p u t e d}$ using alpha $=0.05$.

Table A25. One-Way ANOVA Analysis Output for the Interaction Between Marital Status and Age on New Image.

\begin{tabular}{lccc}
\hline Married = Single & & \\
\hline Between-subjects factors $^{a}$ & & Value Label & $\mathrm{N}$ \\
\hline & & $<27$ & 32 \\
\hline trichotomous age & 0.00 & $27-62$ & 2 \\
& 1.00 & $62+$ & 4 \\
\hline
\end{tabular}

${ }^{\mathrm{a}}$ Married $=$ Single.

Table A26. One-Way ANOVA Analysis Output for the Interaction Between Marital Status and Age on New Image.

\begin{tabular}{|c|c|c|c|}
\hline \multicolumn{4}{|l|}{ Descriptive statistics ${ }^{\mathrm{a}}$} \\
\hline \multicolumn{4}{|c|}{ Dependent variable: NI_prop } \\
\hline trichotomous age & Mean & Std. Deviation & $\mathrm{N}$ \\
\hline$<27$ & 0.6719 & 0.16421 & 32 \\
\hline $27-62$ & 0.8125 & 0.08839 & 2 \\
\hline $62+$ & 0.5938 & 0.11968 & 4 \\
\hline Total & 0.6711 & 0.16029 & 38 \\
\hline
\end{tabular}

a. Married $=$ Single. 
Table A27. One-Way ANOVA Analysis Output for the Interaction Between Marital Status and Age on New Image.

\begin{tabular}{|c|c|c|c|c|c|c|c|c|}
\hline \multicolumn{9}{|c|}{ Tests of between-subjects effects ${ }^{a}$} \\
\hline \multicolumn{9}{|c|}{ Dependent variable: NI_prop } \\
\hline Source & $\begin{array}{l}\text { Type III Sum } \\
\text { of Squares }\end{array}$ & $\mathrm{df}$ & $\begin{array}{l}\text { Mean } \\
\text { Square }\end{array}$ & $\mathrm{F}$ & Sig. & $\begin{array}{c}\text { Partial Eta } \\
\text { Squared }\end{array}$ & $\begin{array}{l}\text { Noncent. } \\
\text { Parameter }\end{array}$ & $\begin{array}{c}\text { Observed } \\
\text { Power }^{c}\end{array}$ \\
\hline Corrected Model & $0.064^{\mathrm{b}}$ & 2 & 0.032 & 1.262 & 0.296 & 0.067 & 2.524 & 0.256 \\
\hline Intercept & 5.528 & 1 & 5.528 & 218.190 & 0.000 & 0.862 & 218.190 & 1.000 \\
\hline trichage & 0.064 & 2 & 0.032 & 1.262 & 0.296 & 0.067 & 2.524 & 0.256 \\
\hline Error & 0.887 & 35 & 0.025 & & & & & \\
\hline Total & 18.063 & 38 & & & & & & \\
\hline Corrected Total & 0.951 & 37 & & & & & & \\
\hline
\end{tabular}

${ }^{\mathrm{a}}$ Married $=$ Single; ${ }^{\mathrm{b}} \mathrm{R}$ Squared $=0.067$ (Adjusted R Squared $\left.=0.014\right) ;{ }^{\mathrm{c} C o m p u t e d}$ using alpha $=0.05$.

\section{Mixed ANOVA Analysis Output}

Table A28. Mixed ANOVA Analysis Output: Mauchly's test of sphericity.

\begin{tabular}{|c|c|c|c|c|c|c|}
\hline \multicolumn{7}{|c|}{ Mauchly's test of sphericity } \\
\hline \multicolumn{7}{|c|}{ Measure: acc } \\
\hline \multirow{2}{*}{$\begin{array}{l}\text { Within } \\
\text { Subjects } \\
\text { Effect }\end{array}$} & \multirow{2}{*}{$\begin{array}{c}\text { Mauchly's } \\
\text { W }\end{array}$} & \multirow{2}{*}{$\begin{array}{c}\text { Approx. } \\
\text { Chi-Square }\end{array}$} & \multirow{2}{*}{ df $\quad$ Sig } & \multicolumn{3}{|c|}{ Epsilon ${ }^{\mathrm{b}}$} \\
\hline & & & & Greenhouse-Geisser & Huynh-Feldt & Lower-bound \\
\hline type & 1.000 & 0.000 & 0 & 1.000 & 1.000 & 1.000 \\
\hline
\end{tabular}

Table A29. Mixed ANOVA Analysis Output: Multivariate statistics SPSS output displaying main effects and interactions for the $\mathrm{z}$ scores of the total NINL_BR and DST on Age.

Multivariate statistics spss output displaying main effects and interactions for the $\mathrm{z}$ scores of the total NINL_BR and DST on Age

\begin{tabular}{|c|c|c|c|c|c|c|}
\hline \multicolumn{7}{|c|}{ Multivariate Tests ${ }^{\mathrm{a}}$} \\
\hline Effect & & Value & $\mathrm{F}$ & Hypothesis df & Error df & Sig. \\
\hline \multirow[t]{4}{*}{ type } & Pillai's Trace & 0.000 & $0.004^{\mathrm{b}}$ & 1.000 & 122.000 & 0.952 \\
\hline & Wilks' Lambda & 1.000 & $0.004^{\mathrm{b}}$ & 1.000 & 122.000 & 0.952 \\
\hline & Hotelling's Trace & 0.000 & $0.004^{\mathrm{b}}$ & 1.000 & 122.000 & 0.952 \\
\hline & Roy's Largest Root & 0.000 & $0.004^{\mathrm{b}}$ & 1.000 & 122.000 & 0.952 \\
\hline \multirow[t]{4}{*}{ type ${ }^{*}$ trichage } & Pillai's Trace & 0.002 & $0.131^{\mathrm{b}}$ & 2.000 & 122.000 & 0.878 \\
\hline & Wilks' Lambda & 0.998 & $0.131^{\mathrm{b}}$ & 2.000 & 122.000 & 0.878 \\
\hline & Hotelling's Trace & 0.002 & $0.131^{\mathrm{b}}$ & 2.000 & 122.000 & 0.878 \\
\hline & Roy's Largest Root & 0.002 & $0.131^{\mathrm{b}}$ & 2.000 & 122.000 & 0.878 \\
\hline
\end{tabular}

Note. $N=126$. Pillai's Trace $F$ statistic was reported. 
Table A30. Post hoc tests for trichotomous age.

\begin{tabular}{|c|c|c|}
\hline Tukey B $\mathrm{B}^{\mathrm{a}, \mathrm{b}, \mathrm{c}}$ & & \\
\hline & \multicolumn{2}{|c|}{ Subset } \\
\hline trichotomous age & $\mathrm{N}$ & 1 \\
\hline $27-62$ & 43 & -0.0738819 \\
\hline $62+$ & 34 & 0.0258344 \\
\hline$<27$ & 48 & 0.0484725 \\
\hline
\end{tabular}

Means for groups in homogeneous subsets are displayed. Based on observed means. The error term is Mean Square (Error) $=.492$. a Uses Harmonic Mean Sample Size $=40.816 .{ }^{\text {b}}$ The group sizes are unequal. The harmonic mean of the group sizes is used. Type I error levels are not guaranteed. ${ }^{c}$ Alpha $=0.05$.

\section{Appendix B. Explanatory Statement}

Early Detection of Cognitive Decline: An investigation of the Novel-Image Novel-Location Task-Bond Revised (NINL-BR) as a potential early detection measure.

Project Number: RO15061

Student Researcher: Katerine-Ann MacKinnon-Lee,

$<$ katerine-ann.mackinnon-lee@student.bond.edu.au>

Supervisor: Dr Mark Bahr, mbahr@bond.edu.au

Explanatory Statement and Participant Informed Consent Form

This research project is concerned with understanding more about the nature and impact of age-related cognitive decline. Specifically, whether the NINL-RB can be utilised as an online early detection measure of cognitive decline. The success of this research is vitally dependent upon the assistance of volunteers like yourself who can contribute to the emerging research in the field of early detection of cognitive decline.

Participation in this research involves completing some biographical information, completing the computer-administered NINL-RB that will include the presentation of everyday images and the digit span task which will include the presentation of randomised number sequences, the DASS-21, The Personal Wellbeing Index-Adult, and The Resilience in Midlife Scale.

The study will take about 30 minutes to complete and any data that you provide is anonymous. This data will be stored at the Bond University on the Gold Coast for five years. You are free to withdraw from the experiment at any time without prejudice. If you have any queries regarding the project or would like to be informed of the overall research findings please contact Dr. Mark Bahr on the following email: mbahr@bond.edu.au.

This study has been approved by the Bond University Human Research Ethics Committee (BUHREC) in accordance with the National Health and Medical Research Council's guidelines. If you would like to discuss your participation in the study, or be informed of the aggregate research findings, please contact the 
research on the above contact details. If you have any complaints concerning the manner in which the research is conducted, please do not hesitate to contact BUHREC quoting the above project number. BUHREC can be contacted on:

Bond University Human Research Ethics Committee C/O Office of Research Services

Bond University, Gold Coast, 4229

Tel: +61 755954194 Fax: +61 755951120

Email: buhrec@bond.edu.au

By clicking proceed, you consent to participating in the above stated research project. You can express your consent to continue by selecting the yes response below. You may withdraw your consent to participate now by selecting No below or you may withdraw your consent to participate at any time without consequence by leaving the online form.

Thank you for your participation.

\section{Socio-demographic questionnaire}

Q1. What is your age in years?

Q2. What is your gender?

Male Female

Q3. Please indicate if you are in a relationship.

Married

De facto/Engaged Divorced - without partner Divorced - new partner Separated

Widowed Single

Q4. Are you taking any medications that might impact on your thinking or ability to operate machinery?

Yes

Please list the medications you are currently taking:

No

Not Sure

The Lubben Social Networks Scale - 6

FAMILY: Considering the people to whom you are related by birth, marriage, adoption, etc.

1) How many relatives do you see or hear from at least once a month?

$\square$ none $\square$ one $\quad \square$ two $\square$ three or four $\square$ five thru eight $\square$ nine or more

2) How many relatives do you feel at ease with that you can talk about private matters?

$\square$ none $\quad \square$ one $\quad \square$ two $\square$ three or four $\square$ five thru eight $\square$ nine or more

3) How many relatives do you feel close to such that you could call on them for help?

$\square$ none $\square$ one $\square$ two $\square$ three or four $\square$ five thru eight $\square$ nine or more

FRIENDSHIPS: Considering all of your friends including those who live in your neighbourhood.

4) How many of your friends do you see or hear from at least once a month? $\square$ none $\square$ one $\square$ two $\square$ three or four $\square$ five thru eight $\square$ nine or more 
5) How many friends do you feel at ease with that you can talk about private matters?

$\square$ none $\square$ one $\quad \square$ two $\square$ three or four $\square$ five thru eight $\square$ nine or more

6) How many friends do you feel close to such that you could call on them for help?

$\square$ none $\square$ one $\quad \square$ two $\square$ three or four $\square$ five thru eight $\square$ nine or more To score responses and interpret the results:

The LSNS-6 total score is an equally weighted sum of these six items. Each LSNS- 6 question is scored from 0 to 5 and the total score ranges from 0 to 30 .

The answers are scored: none $=0$, one $=1$, two $=2$, three or four $=3$, five thru eight $=4$, nine or more $=5$. A score of 12 and lower delineates "at-risk" for social isolation.

Source: Lubben, Blozik, Gillmann, Iliffe, Von Kruse, Beck and Stuck (2006), Gerontologist, 2006, 46, 503-513.

Lubben, J., Blozik, E., Gillmann, G., Iliffe, S., von Renteln Kruse, Beck, J. C., \& Stuck, A. E. (2006). Performance of an abbreviated version of the Lubben Social Network Scale among three European community-dwelling older adult populations. The Gerontologist, 46, 503-513. doi:10.1093/geront/46.4.503

Novel Item Novel Location Task-Bond Revised (NINL_BR)

Example panels of everyday items from the Novel Image Novel Location task (Rizk-Jackson et al., 2006). On the left are panels from the Learning Phase.

On the right are the corresponding panels from the Test Phase, containing a novel location (A), novel image (B), or no change (C).
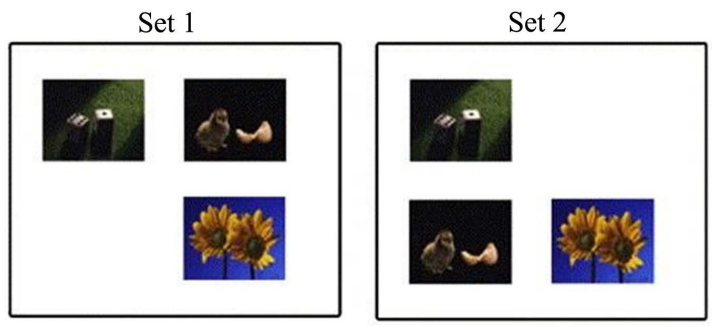

(a)
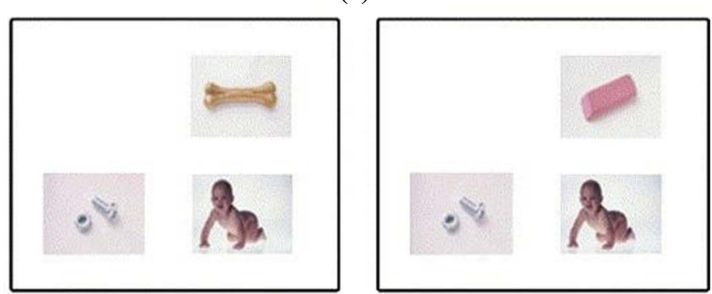

(b)
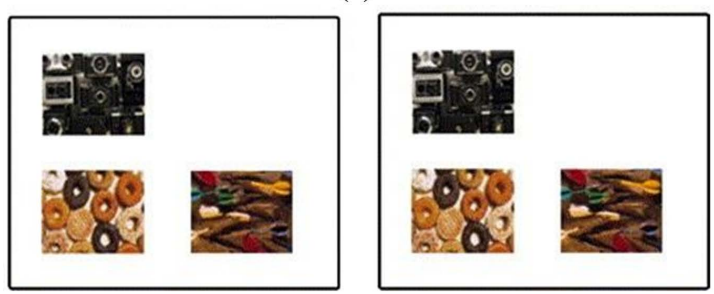

(c) 


\section{The Depression, Anxiety, and Stress Scale (DASS 21)}

Please read each statement and circle a number $0,1,2$ or 3 which indicates how much the statement applied to you over the past week. There are no right or wrong answers. Do not spend too much time on any statement.

The rating scale is as follows:

1) Did not apply to me at all

2) Applied to me to some degree, or some of the time

3) Applied to me to a considerable degree, or a good part of time

4) Applied to me very much, or most of the time

5) I found it hard to wind down

6) I was aware of dryness of my mouth

7) I couldn't seem to experience any positive feeling at all

8) I experienced breathing difficulty (e.g., excessively rapid breathing, breathlessness in the absence of physical exertion)

9) I found it difficult to work up the initiative to do things

10) I tended to over-react to situations

11) I experienced trembling (e.g., in the hands)

12) I felt that I was using a lot of nervous energy

13) I was worried about situations in which I might panic and make a fool of myself

14) I felt that I had nothing to look forward to

15) I found myself getting agitated

16) I found it difficult to relax

17) I felt down-hearted and blue

18) I was intolerant of anything that kept me from getting on with what I was doing

19) I felt I was close to panic

20) I was unable to become enthusiastic about anything

21) I felt I wasn't worth much as a person

22) I felt that I was rather touchy

23) I was aware of the action of my heart in the absence of physical exertion (eg, sense of heart rate increase, heart missing a beat)

24) I felt scared without any good reason

25) I felt that life was meaningless

Depression subscale: Items 3, 5, 10, 13, 16, 17, and 21.

Anxiety subscale: Items 2, 4, 7, 9, 15, and 20.

Stress subscale: Items 1, 6, 8, 11, 12, 14, and 18.

Subscale scores are obtained by aggregating all items on the subscale and multiplying by two.

\section{The Personal Wellbeing Index-Adult, Fifth Edition (PWI-A)}

The following questions ask how satisfied you feel, on a scale from zero to 10 . Zero means you feel no satisfaction at all and 10 means you feel completely satisfied. 
1) How satisfied are you with your standard of living?

2) How satisfied are you with your health?

3) How satisfied are you with what you are achieving in life?

4) How satisfied are you with your personal relationships?

5) How satisfied are you with how safe you feel?

6) How satisfied are you with feeling part of your community?

7) How satisfied are you with your future security?

Total PWI-A score is obtained by summing all items.

\section{The Resilience in Midlife Scale (RIM Scale)}

Please read each statement and indicate the extent to which you agree or disagree:

0) Strongly Disagree

1) Somewhat Disagree

2) Neither Disagree nor Agree

3) Somewhat Agree

4) Strongly Agree

6) Deal with whatever comes my way

7) Achieve my goals

8) My life has meaning

9) Overcome financial difficulties

10) Friends I can confide in

11) Easily discouraged by failure

12) View change as a challenge

13) Can find a solution to a problem

14) In control of my own life

15) Do not cope well with stress

16) Have someone to help me if needed

17) Inability to deal with death

18) Give up when things look hopeless

19) Accept changes to body due to age

20) Can get through difficult times

21) Rely on family in tough times

22) Not equipped to handle changed work conditions

23) Belief in myself gets me through

24) Do not follow through with plans

25) I have little influence over what happens tome

26) Cope positively with illness

27) Love challenges and follow them through

28) Difficulty with loved ones leaving home

29) Control how I respond to events in my life

30) Spiritual beliefs give me hope during loss

Items $6,10,12,13,17,19,20$, and 23 are reverse scored. Total RIM Scale score is obtained by aggregating all items. 


\section{Appendix C}

Observed reliability statistics for the DASS 21 , PWI-A, the RIM scale, and the LSNS-6.

Table C1. Reliability coefficient statistics of the DASS 21.

\begin{tabular}{cc}
\hline Cronbach's Alpha & Number of Items \\
\hline 0.917 & 21 \\
\hline
\end{tabular}

Note. $N=126$. DASS $21=$ The depression, anxiety, and stress scale (Lovibond \& Lovibond, 1995).

Table C2. Reliability coefficient statistics of the PWI-A.

\begin{tabular}{cc}
\hline Cronbach's Alpha & N of Items \\
\hline 0.927 & 7 \\
\hline
\end{tabular}

Note. $N=126$. PWI-A = The personal wellbeing index - adult (The international wellbeing group, 2013).

Table C3. Reliability coefficient statistics of the RIM scale.

\begin{tabular}{cc}
\hline Cronbach's Alpha & N of Items \\
\hline 0.763 & 25 \\
\hline
\end{tabular}

Note $N=126$. RIM Scale $=$ The resilience in midlife scale $($ Ryan \& Caltabiano, 2009)

Table C4. Reliability coefficient statistics of the LSNS-6.

\begin{tabular}{cc}
\hline Cronbach's Alpha & N of Items \\
\hline 0.864 & 6 \\
\hline
\end{tabular}

Note. $\mathrm{N}=126$. LSNS-6 $=$ The lubben social network scale-6 (Lubben \& Gironda, 2003). 